\title{
Meta-Synthesis of Qualitative Case Studies: An Approach to Theory Building
}

Organizational Research Methods 16(4) $522-556$

(C) The Author(s) 2013 Reprints and permission: sagepub.com/journalsPermissions.nav DOI: $10.1177 / 1094428$ I I3484969 orm.sagepub.com

@SAGE

\section{Christina Hoon'}

\begin{abstract}
The purpose of this article is to provide the research design of a meta-synthesis of qualitative case studies. The meta-synthesis aims at building theory out of primary qualitative case studies that have not been planned as part of a unified multisite effect. By drawing on an understanding of research synthesis as the interpretation of qualitative evidence from a postpositivistic perspective, this article proposes eight steps of synthesizing existing qualitative case study findings to build theory. An illustration of the application of this method in the field of dynamic capabilities is provided. After enumerating the options available to meta-synthesis researchers, the potential challenges as well as the prospects of this research design are discussed.
\end{abstract}

\section{Keywords}

synthesis of knowledge, research synthesis, qualitative case study research, theory building

Case study research enables the study of contemporary organizational phenomena in a real-life setting with an in-depth, holistic study of few or single cases (e.g., Flyvbjerg, 2011; Hammersley \& Gomm, 2002; Stake, 2005; Yin, 2009). Given the study's rich history and broad application, case study research has its strength in producing novel theoretical insight stemming from case-specific contextualized findings (Eisenhardt, 1989; Eisenhardt \& Graebner, 2007; Hammersley \& Gomm, 2002; Sigglekow, 2007). In organizational and management research, an increasing number of rich, qualitative case studies generate substantive contributions to a variety of different research areas, such as dynamic capabilities (Ridder, Hoon, \& McCandless, 2009), strategy as practice (Jarzabkowski \& Spee, 2009), or international business (Piekkari, Welch, \& Paavilainen, 2009); yet little accumulation of the understanding gathered from these primary case studies has been gained.

This inattention may stem from the fact that most researchers design their studies to collect new primary data, thereby "overvaluating novelty to the detriment of accumulating convergent findings"

\footnotetext{
'Gottfried Wilhelm Leibniz Universität Hannover, Institute of Human Resource Management, Hannover, Germany

Corresponding Author:

Christina Hoon, Gottfried Wilhelm Leibniz Universität Hannover, Faculty of Economics and Management, Institute of Human Resource Management, Koenigsworther Platz I, 30167 Hannover, Germany.

Email: hoon@pua.uni-hannover.de
} 
(Rousseau, Manning, \& Denyer, 2008, p. 476). Furthermore, procedures for the synthesis of qualitative studies are rare, with a few exceptions in the field of medical science or social policy that have benefited from an evidence-informed synthesis (e.g., Denyer \& Tranfield, 2003; Noblit \& Hare, 1988; Sandelowski \& Barroso, 2007). Losing sight of a qualitative synthesis stands in sharp contrast to the increasing significance of the meta-analysis as the dominant approach to statistically aggregate quantitative evidence (Cooper, 2010; Glass, 1977; Hunter, Schmidt, \& Jackson, 1982). Meta-analysis offers a set of valid methodological choices and procedures aiming to enhance the predictive potential and practical usefulness of organizational and management theory (e.g., Aytug, Rothstein, Zhou, \& Kern, 2012; Carlson \& Ji, 2011; Cortina, 2003; Kisamore \& Brannick, 2008; Schmidt, 2008).

The lack of effort to "put together" empirical insight of primary case studies has important implications for knowledge development in management research. First, the case studies' rich findings reach disparate conclusions about the same phenomenon with interpretations becoming difficult. By calling for further research, in many instances, new studies may produce equally disparate findings (Carlson \& Ji, 2011). Second, the pace of knowledge production is viewed as resulting in nonreconcilable islands of knowledge that do not contribute significantly to our full understanding of a phenomenon of interest (Rousseau et al., 2008; Sandelowski \& Barroso, 2007). More critically, case studies tend to remain isolated, stand-alone works with their potential cumulative advantage for advancing knowledge in the field being neglected. By accumulating evidence on similar research interests, however, theory can be replicated in that a theory is grounded in a broader set of studies that focus on an identical phenomenon in similar settings. Substantive theories grounded in particular research contexts are moved to a more generic theory with a broader application, thereby enabling an analytical generalization (Yin, 2009). Yet the goal of a meta-synthesis is building theory by refining or extending existing theory or by generating theory.

The motivation of this article is to develop the design of a meta-synthesis of qualitative case studies. A meta-synthesis is defined as an exploratory, inductive research design to synthesize primary qualitative case studies for the purpose of making contributions beyond those achieved in the original studies. A meta-synthesis constitutes an understanding of synthesis that is interpretive, aiming at synthesizing primary qualitative case studies that have not been intended as part of a unified multisite effect. By projecting and expanding recent works on meta-analysis, I propose eight steps for conducting a meta-synthesis. As such, the meta-synthesis is understood as a complete study itself that aims at extracting, analyzing, and synthesizing qualitative evidence to build theory.

The contributions of this article to the organizational and management literature are twofold. Conceptually, this article offers a distinction among research synthesis as aggregation, interpretation, and translation of evidence. These perspectives represent different understandings of research synthesis that emerge from the basic paradigmatic positions inherent in organizational research. Then, by drawing on research synthesis as interpretation from a postpositivistic point of view, this article provides and illustrates the research process of building theory via meta-synthesizing case studies. Going beyond conventional or systematic literature reviews (e.g., Rousseau et al., 2008; Tranfield, Denyer, \& Smart, 2003), a meta-synthesis seeks to synthesize the key variables and underlying relationships across a set of published qualitative case studies to arrive at a refined, extended, or even new theory. Given the above, this article may serve as a conceptual and methodological resource to scholars wishing to synthesize qualitative case studies in the field of organizational and management research.

In the following, a brief description of the broader debate around the synthesis of knowledge within the different paradigmatic positions is offered. Afterward, the article presents the research design of a meta-synthesis of qualitative case studies and illustrates its application using the empirical material of seven primary case studies conducted in the field of dynamic capabilities. The article 
concludes with discussing the benefits and limitations that the meta-synthesis approach poses for organizational and management research.

\section{Synthesis of Knowledge in Organizational and Management Research}

The call for a synthesis of knowledge follows the assumption that the foundation of science is the accumulation of knowledge from the research evidence of many studies (Hunt, 1997; Hunter et al., 1982). More generally, meta-studies - the analysis of the analysis - are viewed as being grounded in an understanding of knowledge building as an evolutionary sequence (Glass, 1977). The evolutionary perspective of theorizing is based on an understanding of knowledge accumulation as fragmented processes of selection that involve trials in the form of conjectures and errors in the form of refutation (Campbell, 1974; Weick, 1989). From this point of view, knowledge not only stems from a revolutionary progress (Kuhn, 1962) but can also emerge from a backward-oriented integration of previous evidence (Campbell, 1974).

Within the broader array of synthesis activities (Rousseau et al., 2008), three directions can be found that are either informed by a positivist and quantitative tradition or move beyond the properties of positivism to postpositivism or constructivism to especially highlight the interpretive or translative nature of research synthesis activities. Since these understandings of research synthesis as aggregation, interpretation, and translation are grounded in different assumptions, they produce distinct ways of approaching a synthesis of knowledge. Rather than focusing primarily on philosophical debates or on paradigm conflict in detail, this section presents the central features of research syntheses along with associated views of the paradigmatic approaches of positivism, postpositivism, and constructivism (see Table 1).

\section{Aggregation Synthesis}

Following an understanding of research synthesis as aggregation (Rousseau et al., 2008), metaanalysis has moved to a preferred way of establishing a predictive theory or testing theory (Aytug et al., 2012; Cooper, 2010; Hunt, 1997; Wanous, Sullivan, \& Malinak, 1989). Aggregative synthesis is rooted in and informed by a positivist and quantitative tradition. Within this perspective, knowledge of the "way things are" is conventionally aggregated in the form of time- and context-free generalizations that can take the form of cause-effect laws (Gioia \& Pitre, 1990; Guba \& Lincoln, 1994; Lincoln \& Guba, 1985). A meta-analysis treats study results as primary data and statistically synthesizes bodies of empirical findings that are dispersed across time and publications (e.g., Aguinis, Pierce, Bosco, Dalton, \& Dalton, 2011; Aguinis, Sturman, \& Pierce, 2008; Carlson \& Ji, 2011; Dalton \& Dalton, 2008; Glass, 1977; Schmidt, 2008). The meta-analysis yields an overall estimate of effect size with the detection and estimation of interaction effects being central to the interpretation of the meta-analytic results (Cortina, 2003). Interacting effects provide the boundary conditions of the effects that are hypothesized, thereby generating superior evidence of generalizability as compared with the primary studies (Carlson \& Ji, 2011; Cooper, 2010; Hunt, 1997; Hunter et al., 1982). More specifically, the effect sizes constitute an important indicator of the predictive potential and the practical usefulness of a theory (Aguinis, Pierce, et al., 2011). As such, meta-analyses set the standard for what is considered the state of science, for what is known and where future research is needed in a field, and for which theory is considered valid and which one is not (Schmidt, 2008).

\section{Interpretation Synthesis}

By ascribing a more interpretive component to synthesis, other scholars engage in an inductive form of knowledge synthesis to make interpretations across extant qualitative studies. Going 


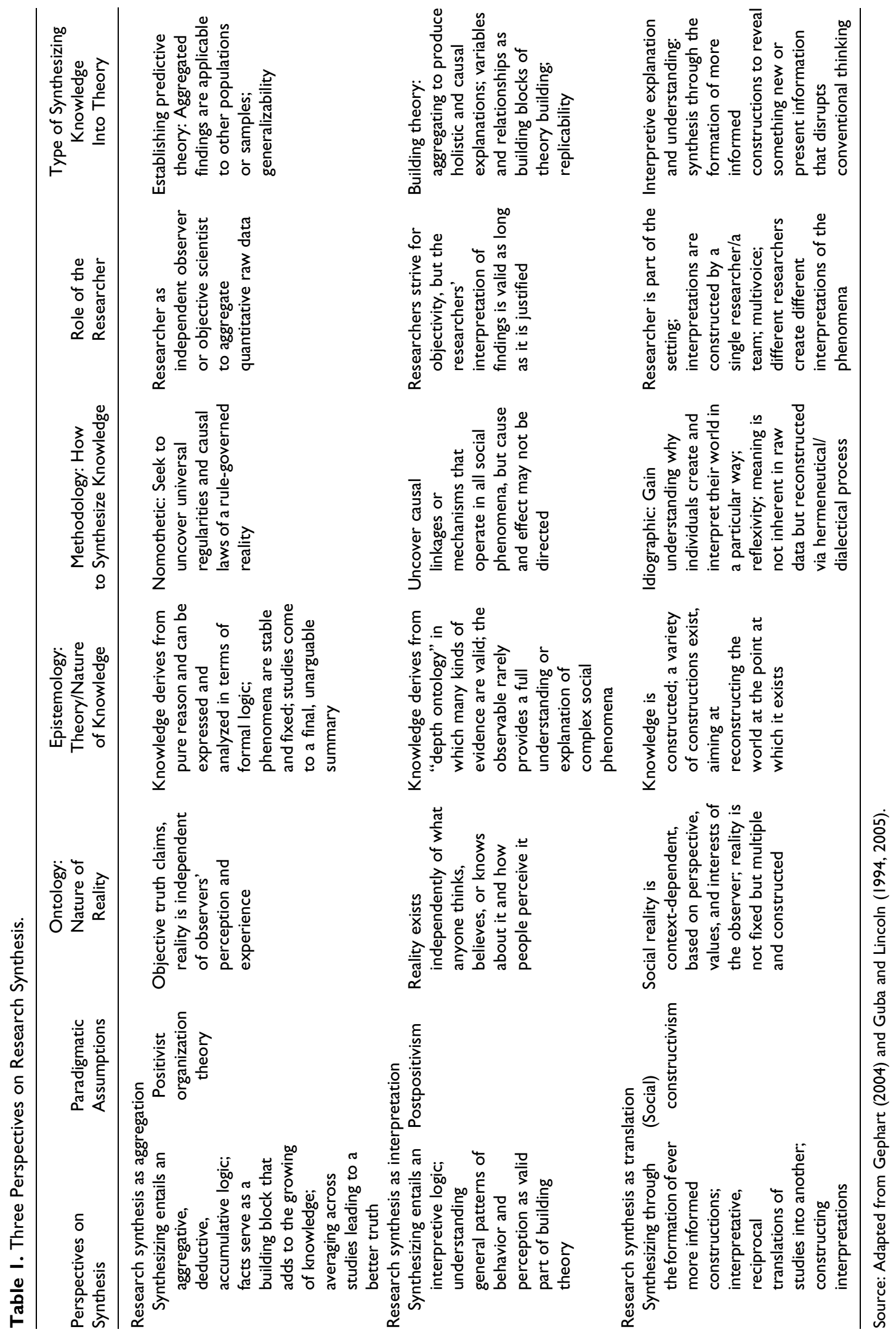


beyond the deductive logic of classical positivism, the postpositivist view embraces that an underlying common reality exists that can be discovered from research (Gephart, 2004). Knowledge is regarded as social facts that are embedded in social actions and evidence from which some lawful and reasonably stable relationships can be found (Miles \& Huberman, 1994). From the subjective, individual, and collective interpretation of these facts, patterns and, later, constructs can be derived that underlie individual and social life (Gioia \& Pitre, 1990; Guba \& Lincoln, 1994). Researchers look for an individual or a social process, a mechanism, or a structure at the core of events that can be captured to offer a causal description of the forces at work (Miles \& Huberman, 1994). Rather than quantitatively aggregating effect size estimates, here, synthesis refers to the accumulation of primary evidence with the purpose to generate interpretive explanation rather than prediction. The synthesis entails extracting and analyzing insights from primary studies to identify categories and patterns that emerge across the studies while attempting to preserve the original studies' integrity. The goal is to make a theoretical contribution with contextualization being a central consideration in that the studies' local contexts are taken into account (Yin, 2009).

\section{Translation Synthesis}

The understanding of research synthesis as translation is especially rooted and applied in medical science, social and political policy, or health care (Denyer \& Tranfield, 2003; Tranfield et al., 2003). From a constructivist perspective, reality is assumed to exist in the form of multiple, intangible mental constructions that are dependent for their form and content of the actors holding these constructions (Gephart, 2004; Guba \& Lincoln, 1994, 2005). Instead of interpreting knowledge as social facts, evidence constitutes any theme or mode of expression that social actors convey with researchers gearing toward an understanding of how individuals construct and reconstruct knowledge about a phenomenon. Data are viewed as "constructed entities," and the goal is to construct ever more informed reconstructions to finally come to a consensus of how to interpret the substance of the evidence (Gioia \& Pitre, 1990). Within this perspective, synthesis entails the informed and meaningful reconstruction of how the study's participants constructed their own understandings. Knowledge is synthesized to better draw science-based recommendations from diverse and fragmented findings, for example, for policy makers and practitioners (Denyer \& Tranfield, 2003; Sandelowski \& Barroso, 2007; Tranfield et al., 2003). Conducting a synthesis embraces hermeneutic or dialectic processes to translate studies into one another with the aim of drawing cross-case conclusions (Noblit \& Hare, 1988).

In this article, an underlying perspective needs to be considered that does not violate but rather preserves the essentials of qualitative case study research while allowing for a synthesis. In this respect, I argue that a meta-synthesis is best accomplished by following the perspective of interpretation synthesis. First, as opposed to the larger constructivist sense of translation synthesis (Sandelowski \& Barroso, 2007), in this perspective, data, analysis, and proceeded insight are treated as separate entities, with data constituting the empirical material on which scientific evidence is based or from which conclusions are drawn. In this respect, interpretation synthesis implies the belief that the case studies' qualitative evidence can be extracted, analyzed, and subsequently synthesized to build theory. Furthermore, along with its postpositivistic perspective interpretation synthesis is apt for tapping into contextual considerations of patterns, variables, and relationships inherent in the primary studies (Miles \& Huberman, 1994). It includes the epistemological position of many case studies conducted in organizational and management research (Piekkari et al., 2009), therefore remaining true to the underlying assumptions of the studies being synthesized (Noblit \& Hare, 1988). 


\section{Meta-Synthesis of Qualitative Case Studies}

Most broadly, case studies range from inductive, interpretive case studies to more indicative, comparative case study research that is used to build theory in a postpositivist and synthetic fashion (Eisenhardt, 1989; Eisenhardt \& Graebner, 2007; Flyvbjerg, 2011; Sigglekow, 2007; Yin, 2009). Case study research is driven from the creation of complex designs to address the unique nature of organizational phenomena with different sets of methods (e.g., Miles \& Huberman, 1994). The researcher who embarks on case study research is usually interested in a specific phenomenon and wishes to understand it completely. This understanding is not generated by controlling variables but rather by observing all of the variables, their interacting relationships, as well as the contextual conditions that are highly pertinent to the phenomenon under study (Eisenhardt, 1989; Eisenhardt \& Graebner, 2007; Flyvbjerg, 2011; Yin, 2009). Case study research has the ability to embrace a variety of data sources and a range of different methodologies leading to in-depth qualitative findings that are bound to their specific contexts (Miles \& Huberman, 1994; Yin, 2009). According to the aforementioned features of case study research, the research design of a meta-synthesis, and in particular its methodological choices and procedures, needs to be broad enough to retain a sense of contextual diversity. At the same time, it requires synthesizing the case studies' rich insights into theory without producing oversimplifications. Accordingly, a meta-synthesis needs to incorporate a broad yet still manageable set of studies in which sensitivity toward the analysis and synthesis of other researchers' findings can be maintained.

A meta-synthesis is defined as an exploratory, inductive research design to synthesize primary qualitative case studies for the purpose of making contributions beyond those achieved in the original studies. This is a meta-study because it involves the accumulation of previous case studies' evidence, and more specifically its extraction, analysis, and synthesis. Consequently, a meta-synthesis does not refer to the reuse of firsthand data stemming from the case researchers' own observations or interviews. Instead, a meta-synthesis occurs at the level at which the original researchers of the primary studies have constructed their insights in accordance with their own understanding and interpretation of the data. In contrast to research reviews seeking to provide a conceptual consolidation of a body of research (Sandelowski \& Barroso, 2007; Tranfield et al., 2003), the benefits of a metasynthesis can be seen in empirically consolidating primary studies to build theory.

As theory building can be differentiated most broadly into extending, refining, or generating theory (Ridder et al., 2009; Ridder, Hoon, \& Baluch, 2012; Snow, 2004), first I consider a metasynthesis to provide the extension of an existing theoretical perspective to a broader range of contextual conditions (Snow, 2004). Here, the meta-synthesis constitutes a replication logic in terms of findings being considered more potent the more cases are shown to support the same theory (Yin, 2009). As such, existing theory is extended from particular research contexts to more generic contexts and is therefore key to the accumulation of knowledge (Colquitt \& Zapata-Phelan, 2007; Edmondson \& McManus, 2007). Second, the close inspection of the aggregated empirical evidence can serve to refine existing theory in terms of a modification, supplementation, or even negation (Burawoy, 1998; Snow, 2004). The variety inherent in the primary studies can lead to the identification of contradictions and deviating evidence that yield counterinstances of an existing theory (Burawoy, 1998; Sigglekow, 2007). Hence, the meta-synthesis can aim to refine existing theory by introducing meaningful factors such as new boundary conditions or situational constraints to an existing relationship or process (Colquitt \& Zapata-Phelan, 2007). Finally, a meta-synthesis is suggested to generate theory. In fact, synthesizing primary case studies is not apt for detecting yet unexplored relationships and processes as the foundation for new theory. However, the metasynthesis can lead to the identification of a new construct or a relationship the existing theory does not account for or to the substantial reconceptualization of an existing construct (Eisenhardt, 1989; Eisenhardt \& Graebner, 2007). Regardless of the type of contribution, subsequent studies can build 
on a meta-synthesis by using a new construct, relationship, mechanism, or process-ordered pathway as an input that informs decisions about samples, contexts, or variables to include in a theory-testing framework. Hence, the meta-synthesis seeks to develop inductive theories that may form bridges from rich qualitative evidence to mainstream deductive research (Eisenhardt \& Graebner, 2007; Shah \& Corley, 2006).

\section{Research Design for Meta-Synthesizing Qualitative Case Studies}

As has been shown so far, meta-synthesizing case studies demands attention to be paid to both analyzing evidence across studies to build theory as well as to ensuring sensitivity toward the contextual considerations of the primary studies. In the following, a research design of a meta-synthesis is proposed of how to build theory via synthesizing qualitative case studies. For developing a rigorous design, I suggest that extending and projecting the method of a meta-analysis into the area of a qualitative synthesis is beneficial. In fact, the meta-analysis relies on an additive model of evidence while downplaying contextual differences (Rousseau et al., 2008). However, it offers a general line of inquiry for exploring variance in relationships across existing studies with these differences being treated as possible intervening variables (Aguinis, Dalton, Bosco, Pierce, \& Dalton, 2011; Cortina, 2003; Dalton \& Dalton, 2008). Second, the activities and procedures inherent in meta-analysis provide a valuable template for how to cope with the requirements evolving from the analysis and synthesis of existing evidence (Hunter et al., 1982; Kisamore \& Brannick, 2008; Wanous et al., 1989). Finally, meta-analyst scholars have generated clear rules of how to report on the conduct of meta-analysis with this replicability being viewed as enhancing the product of a synthesis (Aytug et al., 2012; Carlson \& Ji, 2011; Dalton \& Dalton, 2008). To acknowledge the specific requirements of case study data, Yin's (2009) approach of the cross-case synthesis of independently conducted studies as well as Miles and Huberman's (1994) techniques of a within-case and a cross-case analysis are considered.

In the following section, I turn to a discussion of the steps involved in a meta-synthesis. Each of these steps is illustrated by an example from an ongoing meta-synthesis study that I conducted in the field of dynamic capabilities. A detailed report of the basic actions and procedures used as well as their purpose in the context of my study is summarized in Table 2. Although this protocol is specific to the interests, analytical path, and goal of my study, a meta-synthesis protocol more generally is apt for substantiating the certain path and logic of a meta-synthesis, thereby enhancing validity and reliability (Pratt, 2008).

The research interests of my meta-synthesis study focus on dynamic capabilities. The dynamic capabilities approach aids in understanding how firms can shape, reshape, configure, and reconfigure their resource base to respond to changing environments (e.g., Eisenhardt \& Martin, 2000; Helfat et al., 2007; Teece, Pisano, \& Shuen, 1997). In this area, an increasing body of qualitative case studies explores the processes of dynamic capability development by focusing especially on managers and how they collectively reconfigure resources within changing environments. In recent reviews, scholars have started to map and assess this evolving field (e.g., Di Stefano, Peteraf, \& Verona, 2010; Wang \& Ahmed, 2007); however, until now, the rich body of knowledge on managers' cognitive representations in dynamic capability development has not been accumulated. As an extensive stock of knowledge in a field increases the need to integrate findings in tandem (Aytug et al., 2012), the motivation for my work was to synthesize primary case studies to build theory on the link between managerial cognitive representations and the development of dynamic capabilities.

\section{Step I: Framing the Research Question}

In the first step, I studied the existing literature on dynamic capabilities for the clear identification of a problem or a phenomenon. Whether a guiding theory, a set of competing models, or a point of view 


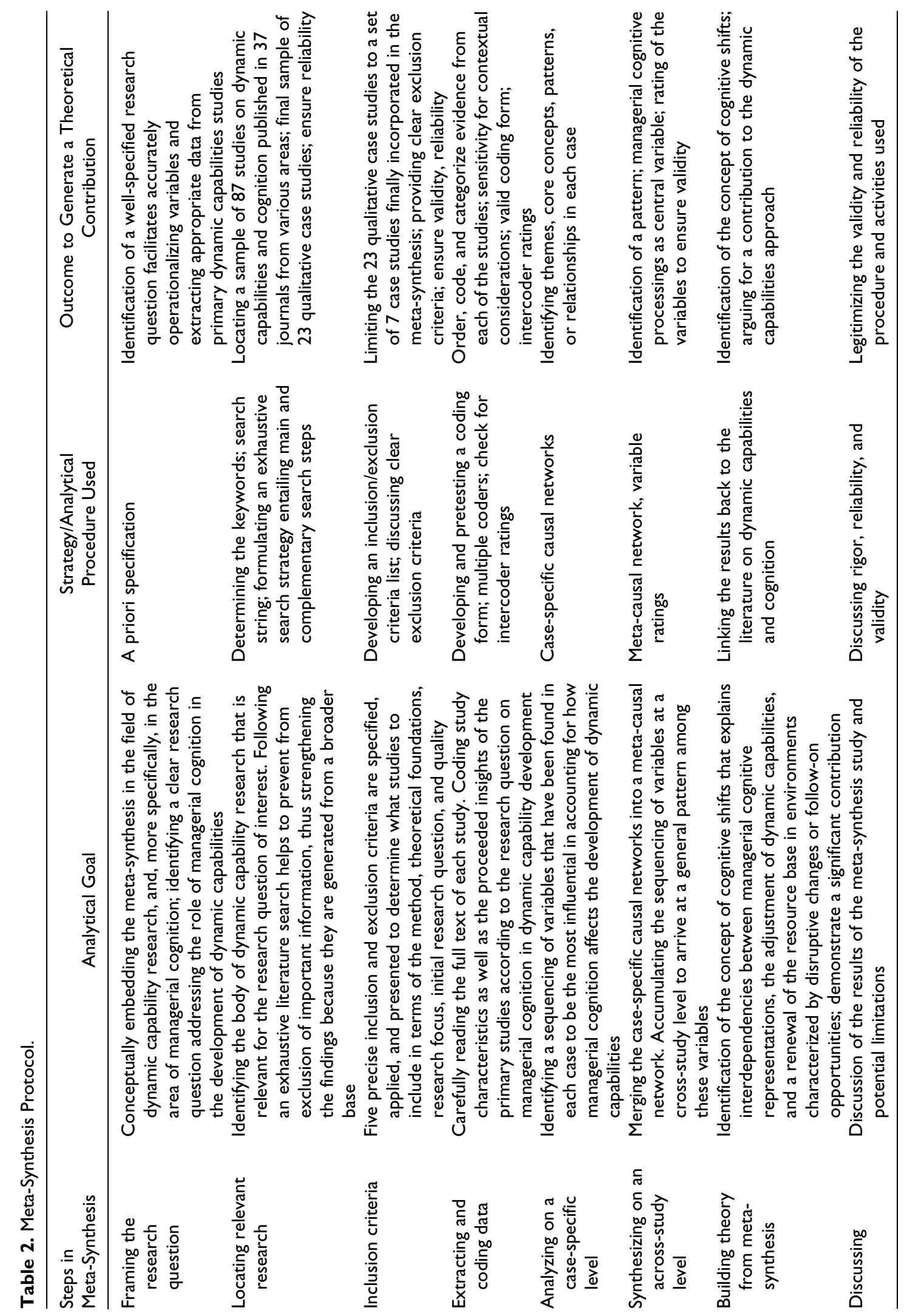


about a topic, a meta-synthesis starts with a conceptual framing of the topic. For organizing the meta-synthesis, I referred to the dynamic capabilities approach with my interest gravitating toward recent works seeking to advance our understanding of the development of dynamic capabilities by focusing on creative managerial and entrepreneurial acts (Augier \& Teece, 2009; Eisenhardt \& Martin, 2000; Helfat et al., 2007). Within this view managers are seen as playing a central role in identifying strategic opportunities, in orchestrating organizational assets, and in capturing business models and new organizational forms (Augier \& Teece, 2009). By referring to dynamic capabilities from a managerial cognition approach (Gavetti, 2005), empirical studies have increasingly explored what managers interpret and act on and found that managerial perceptions affect the behavior toward the renewal of the firm's resource base. To build on these studies, I formulated a first broad research topic on the role of cognition in the development of dynamic capabilities. Through a series of iterations that involved testing this topic against the current literature and existing empirical studies, a more nuanced research question emerged. Finally, I focused the meta-synthesis on this research question: "How and why do managerial cognitive representations shape the development of dynamic capabilities?" Addressing this research question aids in aggregating the current knowledge of managers interpreting and acting on dynamic capabilities, thereby providing theoretical insight into managerial cognitions affecting the development of dynamic capabilities in dynamic, highly contested environments.

In contrast to the broader research interests of a conventional literature review or a systematic review (Denyer \& Tranfield, 2003), a meta-synthesis takes advantage of a well-specified, theoretically informed research question. In my study, the well-specified research question informed the specification of the range of studies to synthesize and enabled me to extract appropriate evidence from the primary studies. Up to a point, it is proposed that the more fine-grained and narrow the research question, the greater the conceptual clarity and interpretability of the results (Yin, 2009). However, any advantage gained from the interpretability of empirical results is offset by considerations of the availability of evidence for the meta-synthesis. During the further conduct of my metasynthesis, the research question proved to be broad enough to open up a relevant set of high-quality case studies, while its narrowness enabled to identify a set of studies that corresponded to my topic of interest.

\section{Step 2: Locating Relevant Research}

In the next step, I started to identify the bodies of research that can be deemed to be relevant for my meta-synthesis interest. To locate the set of existing qualitative case studies, I based the search on the Social Science Citation Index (SSCI) database of Thomson-ISI Web of Science. As an initial search based on the search string "dynamic capabilities" OR "dynamic capability" AND "cogn*" AND "case stud*" yielded no valid results, I realized that this search string was too narrow. Consequently, I began more broadly by retrieving all articles that were published in the Business and Management categories of the ISI Web of Science database with topics containing the expressions "dynamic capability" or "dynamic capabilities." This yielded a set of 1,604 contributions. I refined the search by reducing the set of contributions to the keyword "cognition" and the derivatives of the root "cogni" (cogni*: cognition, cognitions, cognitive, cognizance). A main search using the terms "dynamic capability" OR "dynamic capabilities" in combination with "cogni" generated valid results, revealing that no additional terms were needed. These keywords were used as a selection criterion in topic (title, keyword, abstract), resulting in an initial sample of 81 contributions published in journals or book chapters/conference proceedings. This basic search was complemented by cross-checking the resulting article list with the sample of articles found in reviews conducted in the field of dynamic capabilities. In addition, the journals having received the most hits during the database search were manually searched from 1997 to the present for the keywords of "dynamic 
capabilit*" AND "cogni*" AND "case stud*" at Wiley Online Library. As a result, six more articles were found that had not already been identified by the electronic database search. For the literature search strategy see Table 3.

Overall, a sample of 87 studies was identified, published between January 1997 and August 2012. The year 1997 was chosen as the starting point of the search because this was the year in which Teece et al. (1997) laid the theoretical foundations for the development of this research field. The search incorporated 37 journals with different rankings and stemming from various business areas, thereby acknowledging the widespread use and publication of dynamic capability studies in areas such as strategic management, entrepreneurship, or product innovation. In addition, this broad set of journals contains venues that are viewed as especially open for publishing qualitative case study research, such as the British Journal of Management and Journal of Management Studies.

After a first screening of the titles and the abstracts, 16 articles were identified as false positives and excluded due to irrelevant citations $(n=71)$. Most interesting, the yield of relevant studies was lower from articles categorized as conference proceedings than journal articles. Eight of the 12 articles published in conference proceedings were excluded, compared with 8 of the 75 being categorized as journal articles. While identifying the qualitative case studies within the subset of the 71 articles, it became obvious that the abstracts and keywords varied considerably in their content, with some failing to state the research method used. After obtaining the articles' full text versions, I manually screened and categorized the articles' introductory sections and/or methods sections and categorized them more broadly as conceptual works (16), review studies (2), quantitative studies (23), or qualitative research studies (30). Finally, each of the 30 qualitative research studies was identified as a grounded theorizing study (2), historical analysis (3), process research (2), or qualitative case study (23). Overall, the full-text search generated a list of 23 qualitative case studies referring to dynamic capabilities and managerial cognition. For a list of the initial sample of articles retrieved from the literature search as well as their categorization see Appendix A.

Ideally, any synthesis should be exhaustive in its inclusion of studies by selecting the maximum number of eligible primary sources (Aytug et al., 2012; Kisamore \& Brannick, 2008). By focusing my search strategy on published articles, conference proceedings, and book chapters, I discarded dissertations and unsubmitted or unpublished research studies. Relying on published literature is not without risk since only a comprehensive search is associated with limiting the potential of publication bias (Kepes, Banks, McDaniel, \& Whetzel, 2012; McDaniel, Rothstein, \& Whetzel, 2006). However, benefits of precluding unpublished articles entail the increased scientific rigor resulting from a peer-reviewed publication process as well as the availability of these works for evaluating the sources the meta-synthesis relies on. Similar to the file-drawer problem (Dalton, Aguinis, Dalton, Bosco, \& Pierce, 2012), it can be proposed that the type of empirical research being conducted may also affect the likelihood of publication. More critically, qualitative studies are assumed to be less likely or even more difficult to get published, especially in top-tier journals. Searching within a broad range of journals enabled me to incorporate higher to lower ranked venues from the various disciplines the dynamic capabilities research is rooted in. Furthermore, the use of complementary electronic and manual search techniques ensured that material is not missing either through the inadequacies of indexing or through the selective coverage of databases. Taken together, a systematic, explicit, and transparent search process generates a rigorous meta-synthesis study, thereby acknowledging that ill-defined or biased searches are likely to result in an inadequate database and later, inaccurate results (Aytug et al., 2012; Cooper, 2010).

\section{Step 3: Inclusion/Exclusion Criteria}

The next step in the conduct of the meta-synthesis is the appropriate inclusion of relevant qualitative case studies. Specifying and applying the inclusion/exclusion criteria is considered as being of 
Table 3. Literature Search Strategy.

I. Main Search: Electronic Database Search: Web of Science: Search of the topic (title, abstract, keywords) in published articles in the field of economy and management (Search string: SSCI Web of Science: Topic = (dynamic capability) OR Topic $=$ (dynamic capabilities); refined by Web of Science Categories = (MANAGEMENT OR BUSINESS) AND Document Types $=($ ARTICLE OR MEETING OR BOOK) AND Languages $=($ English $)$ AND Topic $=($ cogni $*))$

Journal

Academy of Management Journal

AOM Annals

AOM Review

British Journal of Management

Creativity and Innovation Management

Entrepreneurship Theory and Practice

Group Decision and Negotiation

Human Resource Management Review

IEE Transactions of Engineering Management

Industrial and Corporate Change

Industrial Marketing Management

Industry and Innovation

International Journal of Service Industry Management

International Journal of Technology Management

Journal of Business Research

Journal of Business Venturing

Journal of Evolutionary Economics

Journal of Institutional Economics

Journal of Management

Journal of Management Information Systems

Journal of Management and Organization

Journal of Management Studies

Journal of Product Innovation Management

Journal of Service Research

Management Decision

Management Learning

Organization Science

Organization Studies

Public Choice

R\&D Management

Research in Organizational Behavior

South African Journal of Business Management

Strategic Entrepreneurship Journal

Strategic Management Journal

Strategic Organization

Technology Analysis and Strategic Management

Technovation
Coverage: Date Searched

January 1997-August 2012

January 1997-August 2012

January 1997-August 2012

January 1997-August 2012

January 1997-August 2012

January 1997-August 2012

January 1997-August 2012

January 1997-August 2012

January 1997-August 2012

January 1997-August 2012

January 1997-August 2012

January 1997-August 2012

January 1997-August 2012

January 1997-August 2012

January 1997-August 2012

January 1997-August 2012

January 1997-August 2012

January 1997-August 2012

January 1997-August 2012

January 1997-August 2012

January 1997-August 2012

January 1997-August 2012

January 1997-August 2012

January 1997-August 2012

January 1997-August 2012

January 1997-August 2012

January 1997-August 2012

January 1997-August 2012

January 1997-August 2012

January 1997-August 2012

January 1997-August 2012

January 1997-August 2012

January 1997-August 2012

January 1997-August 2012

January 1997-August 2012

January 1997-August 2012

January 1997-August 2012

Number of Relevant Articles $(n=68)$

(I)

Number of Relevant Coverage: Date Searched Articles $(n=13)$

Conference Proceedings/Book Chapter

January 1997-August 2012

January 1997-August 2012

Proceedings of the 12th European Conference on Knowledge Management, 20I I, Germany, Vols. I, 2

PICMET 2010: Technology Management for Global Economic Growth, 2010, Portland, OR

January 1997-August 2012

( I) 
Table 3. (continued)

\begin{tabular}{|c|c|c|}
\hline Conference Proceedings/Book Chapter & Coverage: Date Searched & $\begin{array}{c}\text { Number of Relevant } \\
\text { Articles }(n=13)\end{array}$ \\
\hline $\begin{array}{l}\text { Proceedings of the 5th European Conference on Innovation and } \\
\text { Entrepreneurship, 2010, Greece }\end{array}$ & January 1997-August 2012 & $(2)$ \\
\hline Eighth Wuhan International Conference on E-Business, 2009, China & January 1997-August 2012 & (I) \\
\hline $\begin{array}{l}\text { Proceedings of the 10th European Conference on Knowledge } \\
\text { Management, Vols. I-2, 2009, Italy }\end{array}$ & January 1997-August 2012 & (I) \\
\hline $\begin{array}{l}\text { Proceedings of the European Conference on Intellectual Capital, } \\
2009 \text {, Netherlands }\end{array}$ & January 1997-August 2012 & $(\mathrm{I})$ \\
\hline $\begin{array}{l}\text { Proceedings of the Fifths International Symposium on Management of } \\
\text { Technology, 2007, China }\end{array}$ & January 1997-August 2012 & ( \\
\hline $\begin{array}{l}\text { Proceedings of the International Conference on Management Science } \\
\text { and Engineering, 2007, China }\end{array}$ & January 1997-August 2012 & ( 1 ) \\
\hline $\begin{array}{l}\text { Proceedings of the International Conference on Industrial Engineering } \\
\text { and Engineering Management }\end{array}$ & January 1997-August 2012 & ( 1 ) \\
\hline $\begin{array}{l}\text { Proceedings of the International Conference on Intellectual Capital, } \\
\text { Knowledge Management, and Organizational Learning }\end{array}$ & January 1997-August 2012 & (I) \\
\hline
\end{tabular}

II. Complementary Search

I. Manually screening the references in past reviews conducted in the field of dynamic capabilities for the keywords cognition AND case study

\begin{tabular}{|c|c|c|c|}
\hline Review Articles & Type of Review/Data Coverage & Total Number of Articles & $\begin{array}{l}\text { Number of } \\
\text { Additional Relevant } \\
\text { Articles }(n=3)\end{array}$ \\
\hline Barreto $(2010)$ & $\begin{array}{l}\text { Selected review of research on } \\
\text { dynamic capabilities between } \\
1997 \text { and } 2008\end{array}$ & 38 & $\begin{array}{l}\text { Pablo et al. (2007), } \\
\text { Rosenbloom (2000), } \\
\text { Salvato (2003) }\end{array}$ \\
\hline $\begin{array}{l}\text { Di Stefano, Peteraf, } \\
\text { and Verona (2010) }\end{array}$ & $\begin{array}{l}\text { Exhaustive review of dynamic } \\
\text { capability articles between } \\
\text { I995 and } 2008\end{array}$ & 40 & \\
\hline Wang and Ahmed (2007) & $\begin{array}{l}\text { Review of key empirical studies } \\
\text { pertinent to dynamic } \\
\text { capabilities between } 1995 \\
\text { and } 2005\end{array}$ & 32 & \\
\hline $\begin{array}{l}\text { Zahra, Sapienza, and } \\
\text { Davidsson (2006) }\end{array}$ & $\begin{array}{l}\text { Representative review of } \\
\text { studies on capability } \\
\text { development between } 1995 \\
\text { and } 2005\end{array}$ & 16 & \\
\hline \multicolumn{4}{|c|}{$\begin{array}{l}\text { 2. Manual search in five key journals publishing dynamic capability research: Electronic database: Wiley Online Library: } \\
\text { Search of 'full text" in published works in the field of management (Search string: 'dynamic capabilit' AND 'cogni*' } \\
\text { AND 'case stud*' IN 'full text') }\end{array}$} \\
\hline Journals & \multicolumn{2}{|c|}{ Coverage: Date Searched } & $\begin{array}{l}\text { Number of } \\
\text { Additional Relevant } \\
\text { Articles }(n=3)\end{array}$ \\
\hline $\begin{array}{l}\text { British Journal of Management, } \\
\text { Industrial and Corporate } \\
\text { Change, Journal of } \\
\text { Management Studies, } \\
\text { Organization Science, } \\
\text { Strategic Management } \\
\text { Journal }\end{array}$ & \multicolumn{2}{|c|}{ January 1997-September 2012} & $\begin{array}{l}\text { Holbrook (2000), } \\
\text { Martin (2011), } \\
\text { Salvato (2009) }\end{array}$ \\
\hline
\end{tabular}


central importance since the validity of a synthesis depends on the quality of the primary studies on which it is based (Dalton \& Dalton, 2008). According to my research question, I defined clear inclusion/exclusion criteria, which are presented in Table 4.

Following these predetermined criteria, I excluded case studies if they were quantitative in character or if they used cases as an illustrative example, thereby reducing the sample of 23 studies to 21 studies. In addition, I included only articles explicitly framing the study in the dynamic capabilities approach. Given the plurality of meaning embedded in the term "dynamic capabilities" and taking into consideration that dynamic capability scholars have used this term in a variety of different ways (e.g., core competency, adaptive capability, absorptive capability, innovative capability), I looked for empirical articles that follow the seminal definition by Teece et al. (1997, p. 515) and focus on dynamic capabilities as the processes that are directed toward a change in the firms' resource base. Furthermore, the meta-synthesis was limited to studies that provide a substantive contribution to managerial cognitions in the processes of dynamic capability development. A final step entailed reducing to studies whose a priori research question or purpose refers to managerial cognition in the development of dynamic capabilities $(n=9)$. Applying this strict criterion enables maintaining that the evidence on managerial cognitive representations was not collected incidentally. More specifically, only studies were included in which the development of dynamic capabilities and its associated managerial cognitive representations are deliberately described by the studies' participants rather than arbitrarily labeled by the researchers. According to this criterion, two more case studies were excluded. Overall, the final sample consisted of seven studies that were all checked in terms of their quality. I ensured that all studies provide a clear linkage between theory and empirical evidence and reflect the methodological standards that scholars such as Yin (2009) and Eisenhardt (1989; Eisenhardt \& Graebner, 2007) have induced to the field. No further studies were excluded.

Overall, 30 articles ( $35 \%$ of the total number of hits of 87 ) were read in full text, and 7 of these met the study inclusion criteria and were ultimately incorporated in the meta-synthesis (see Appendix B). These seven studies were conducted between 2000 and 2010 in different countries and industries, involving firms that were concerned with the development of dynamic capabilities in dynamic, highly contested environments. The studies under synthesis aim at extending or building theory with the use of multiple data sources following a clear research question. They entail both single cases and multiple cases and use different case study designs, ranging from inductive theory building to the extended case method. All cases explicitly describe the methods of analysis, thereby applying research strategies consistent with best practices as recommended by Eisenhardt (1989) or Yin (2009).

\section{Step 4: Extracting and Coding Data}

A further step is to extract, code, and categorize evidence from the studies under synthesis (Noblit \& Hare, 1988). With regard to the empirical material a meta-synthesis is based on, it is important to note that the meta-synthesist operates at the level at which the original researchers have constructed insights according to their own understanding and interpretation of the data. Instead of the raw data of the primary studies, the proceeded insights that the researchers of these studies have generated constitute the "data" of a meta-synthesis.

To obtain the data necessary for my meta-synthesis, first, a coding form was developed according to the question of interest (Duriau, Reger, \& Pfarrer, 2007). After generating a set of a priori notions about what items to code, together with a coresearcher familiar with the field of dynamic capability research, we read through three randomly selected studies to identify further coding items that might be relevant, thereby constantly refining and modifying the coding form. We also included open-ended questions and blank spaces into the coding form to ensure that the proceeded insights could be recorded as they were portrayed by the original researcher, thereby conversing with as much of the original information as possible. The coding form with its 42 coding items is presented in Table 5 . 
Table 4. Inclusion/Exclusion Criteria.

Criteria Rationales Reasons for Exclusion

(I) Qualitative case study

(2) Articles initially framed in the dynamic capabilities approach and referring to the seminal notion of dynamic capabilities (Teece et al., 1997)

(3) Refer to the processes of dynamic capability development and provide strong focus on cognition

(4) Focus on managerial cognition in the study's a priori goals, research question, research interests

(5) Check quality
I used this criterion to narrow the metasynthesis to articles relying on qualitative case studies. The criterion ensures that there is no difference between the research method the primary researchers claim to have used and the approach actually used. Articles are excluded that use, for example, illustrative case examples to give an in-depth example of how a framework can be applied and that were not collected purposely to understand dynamic capabilities. In addition, case studies primary relying on quantitative data are excluded.

I based the choice on dynamic capabilities to focus specifically on articles in which the authors build on Teece et al. (1997) seminal notion of dynamic capabilities as "the firm's ability to integrate, build, and reconfigure internal and external competences to address rapidly changing environments. Dynamic capabilities thus reflect an organization's ability to achieve new and innovative forms of competitive advantage given path dependencies and market positions." Articles are also included that are theoretically framed in the dynamic capabilities approach, thereby drawing on an understanding of dynamic capabilities as provided by Eisenhardt and Martin (2000).

I used this criterion to identify the case studies on the development of dynamic capabilities that have a strong emphasis on managerial cognitive representations. This entails the inclusion of articles that provide a substantive contribution to the role of managerial cognition in the processes of dynamic capability development.

This criterion enables including dynamic capability studies whose a priori research question(s) or goal(s) are closely connected to managerial cognition.

Therefore, case studies are included that provide a primary focus on the cognitive approach to explain changes in the development of dynamic capabilities.

I checked all studies with regard to quality. According to recent standards and guidelines (Eisenhardt, 1989; Yin, 2009) I checked the studies in terms of rigorous reporting style, clear linkage between theory and empirical evidence, clear contextualization of the case, multiple data sources, clarity concerning the theoretical purpose.
Illustrative case examples (Agarwal \& Helfat, 2009; Taylor \& Helfat, 2009)

Relying on a broader understanding of dynamic capabilities, e.g., path dependency, innovation capability, heuristics, learning, knowledge (Bingham \& Eisenhardt, 20 I I; Demartini, 2007; Dixit et al., 2007; Lanzara \& Patriotta, 2007); referring to dynamic capabilities approach only in the discussion/ contributions part (Aspara et al., 20I I; Gilbert, 2006; Salvato, 2003; van Riel \& Lievens, 2004)

No focus on the development of dynamic capabilities (Autio et al., 201 I; Boerjesson \& Elmquist, 20I I; Holbrook, 2000; McDermott \& Coates, 2007)

Managerial cognition perspective not included in the initial research question (Martin, 20I I; Pablo et al., 2007)

No further studies were excluded due to quality assessment 


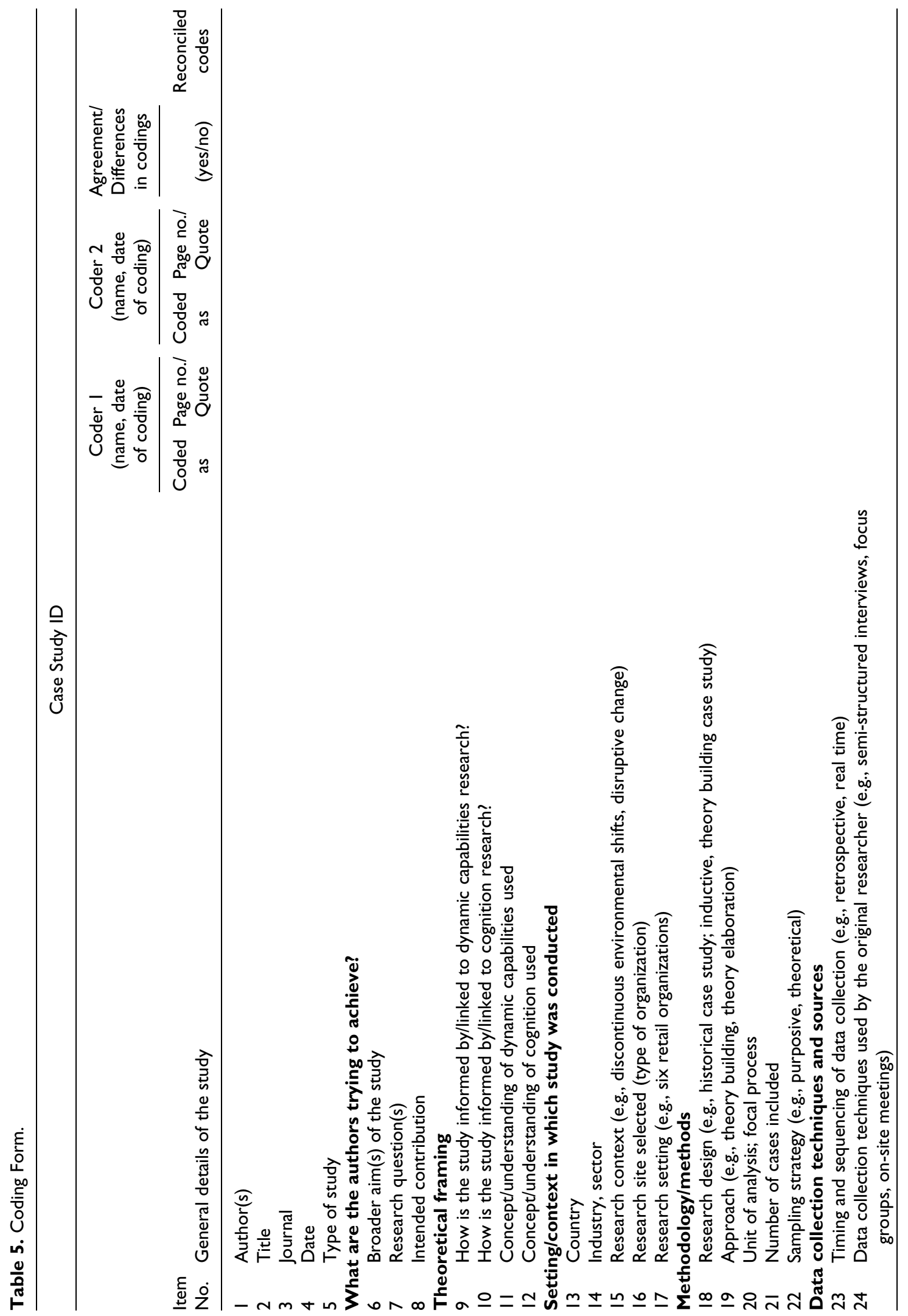




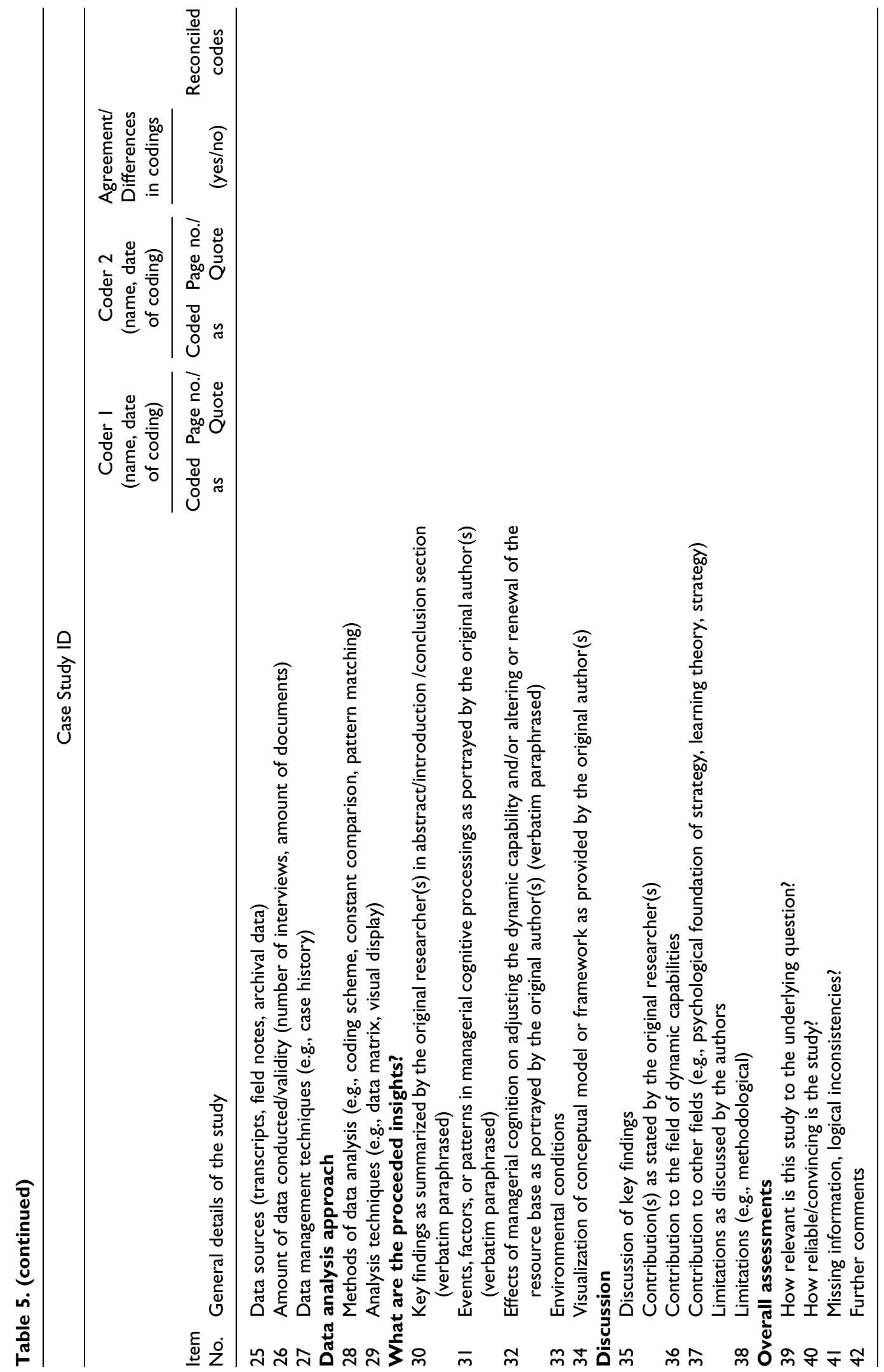


Together with the coresearcher, we coded each primary study for the descriptive characteristics such as type of case study design, setting, number of cases, or data sources. We carefully read each of these studies and then independently coded them according to the coding form. After completing the individual extractions we merged the individual coding forms into a combined database. Coding a broad range of different study characteristics was beneficial as it not only informed us about the specific nature of the body of studies under synthesis but also sensitized us for potentially relevant contextual factors.

To record the relevant evidence from each of the studies included in the meta-synthesis, we especially focused on the findings section and the discussion/contribution section. Concepts similar to dynamic capabilities (e.g., capabilities, organizational capabilities) were coded only if the specific understanding of the construct overlapped significantly with the primary definition used in this study. At the same time, we coded evidence on the concept of cognition as well as similar notions such as "mental models," "attention allocation," "resource cognition," and "cognizance." Following the aforementioned understanding of dynamic capability development and managerial cognition, we listed the events, factors, and patterns that occurred around the "managerial cognitive processings" as well as how they influenced, facilitated, or hindered the "adjustment of a dynamic capability" and turned these elements into variables. This also included listing information on any potential contextual variables in which these managerial cognitive processings appeared such as situational aspects, social systems, or environmental conditions.

As a critical decision in research synthesis entails what features to code (Aytug et al., 2012; Kisamore $\&$ Brannick, 2008), the process of extracting and coding data was guided by a reliable and valid coding form. To ensure inter-reviewer consistency during the course of coding, any discrepancies that emerged were carefully documented in the coding form and resolved by discussions and further rereadings of the original studies. The emergent codes were subsequently fed into the coding form. Overall, working with two synthesizers - both as readers and coders - is beneficial for reducing mistakes in data recording as well as for avoiding the omission of relevant material (Miles \& Huberman, 1994).

\section{Step 5: Analyzing on a Case-Specific Level}

For analyzing the studies under synthesis, first, a technique has to be applied that not only allows for an analysis on a case-specific level but also is apt for addressing the meta-synthesis research question and aims. As I was interested in the intersection between managerial cognitive representations and the processes of dynamic capabilities development, a causal network technique was chosen (Miles \& Huberman, 1994). We explored each case study in terms of the variables which logically influence others, which variables are likely to appear together and which not, and which variables have to happen first for others to happen later (Miles \& Huberman, 1994). Carefully mapping each case in a case-specific causal network alerted me to the variables that go together and contrast with other variables, thereby inviting a closer look at what might be an underlying theme or pattern. As a result, seven case-specific causal networks emerged that connect the particular variables and relationships found in each case into a coherent picture. One of these causal networks, for example, displays that the variable of "preexisting managerial cognitive representations" affects the way in which a dynamic capability is created. If these mental models become inaccurate, for example, due to disruptive environmental changes, they foster the development of a "dysfunctional dynamic capability," thereby hindering a "change in the firm's resource base" (Danneels, 2010).

To ensure the validity of the causal networks, together with my coresearcher, we independently developed each of these displays. Divergent judgments on variables and/or a potential relationship were assessed, recorded, and resolved to capture the substantive issues relevant to the interpretation. Overall, the causal networks proved to be beneficial in my study as they enabled both reflection on the cases' salient properties of the context as well as the combination of particular 


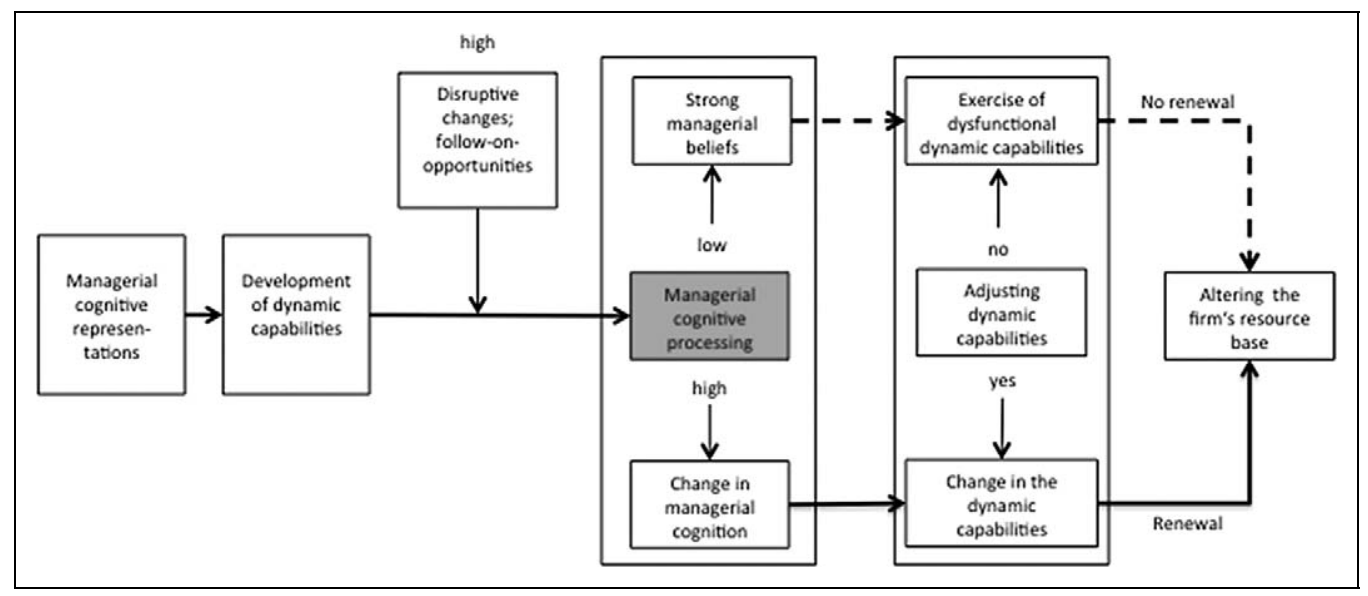

Figure I. Meta-causal network.

instances around dynamic capability development into a more general pattern. However, further techniques for analyzing primary qualitative evidence such as chronological displays, causal maps, or a processual matrix may be viable depending on a meta-synthesis's specific research question, interest, and goal.

\section{Step 6: Synthesis on a Cross-Study Level}

To move from a case-specific level to a cross-study level analysis, the next step was to merge the sequences of variables identified in each of the case-specific causal networks into a meta-causal network. The case-specific causal networks provide the foundation to further explore how the studies under synthesis are related or dissonant through a compare and contrast exercise at a cross-case study level (Miles \& Huberman, 1994). As such, a meta-causal network goes beyond the individual studies to let mechanisms, causalities, or causal conditions and their outcomes emerge from the analysis across a set of studies (Miles \& Huberman, 1994). We matched each case-specific causal network to see how specific variables performed across the complete set of cases. As a result, a metacausal network emerged incorporating a pattern of a sequencing of variables that were found to be meaningful across all cases, namely "managerial cognitive representations," "dynamic capability development," "environmental conditions," "managerial cognitive processing," "adjustment of dynamic capabilities," and "altering the resource base" (see Figure 1).

In particular, the variable of managerial cognitive processing turned out to be central for explaining this pattern, with a low scope of cognitive processing inhibiting the adjustment of a dynamic capability. For instance, the exercise of less appropriate dynamic capabilities was affected by low managerial cognitive processing through which managers were constrained in coping with changing environments. In turn, no alteration of the resource base was achieved. In contrast, a high scope of cognitive processing was associated with an adjustment of the dynamic capability, thereby leading to a renewal of the resource base.

To test and refine this emerging pattern (Miles \& Huberman, 1994), I assessed the variance in environmental change, managerial cognitive processing, adjustment of dynamic capabilities, and renewal of the resource base in each of the studies, thereby enhancing the validity of the emerging pattern (Miles \& Huberman, 1994). In this respect, the variable rating list in Table 6 indicates that in disruptive changes or turbulent environments, extensive managerial cognitive processings are associated with a change in managerial cognition that leads to an adjustment of a dynamic capability, and, in turn, to a 


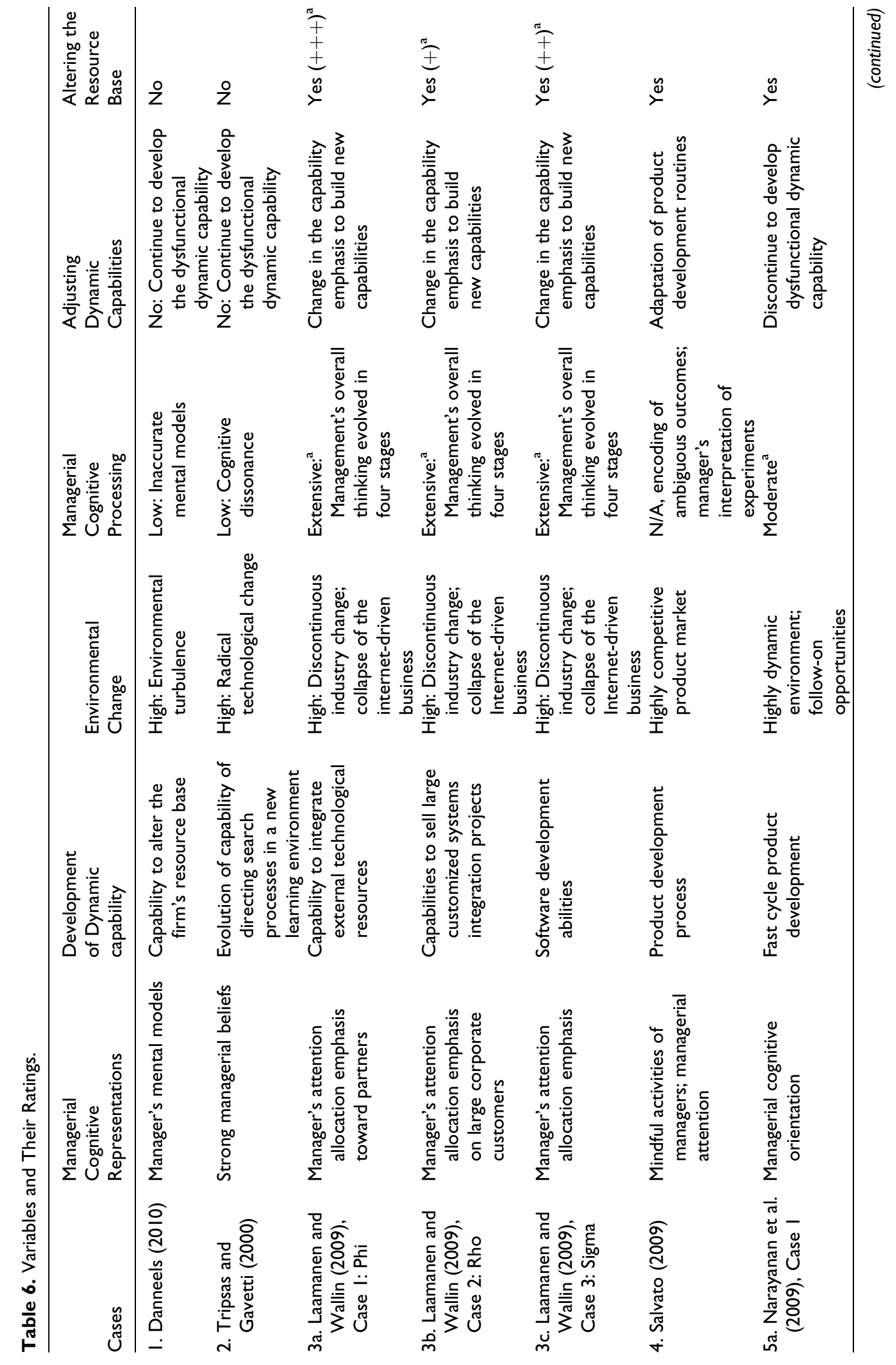




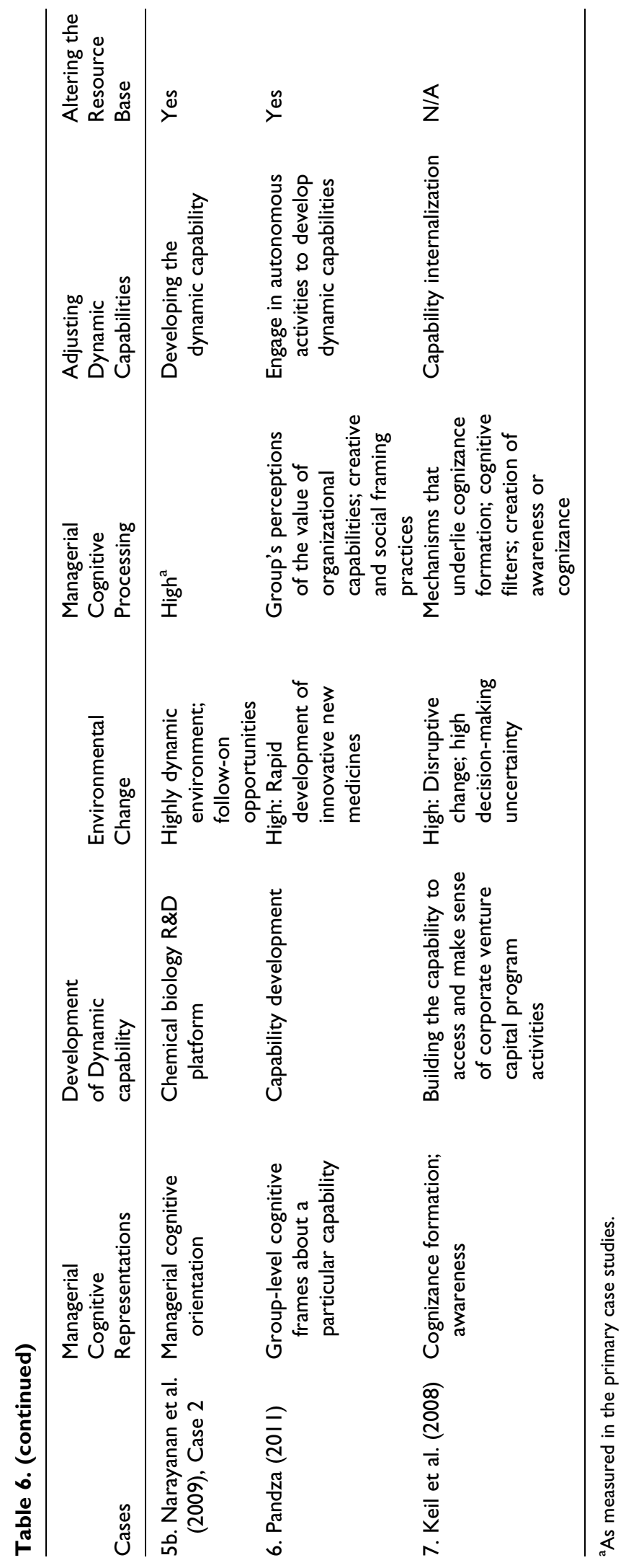


change in the resource base. However, the exercise of dysfunctional dynamic capabilities is associated with low managerial cognitive processing resulting in inaccurate mental models (see Table 6).

Overall, a pattern of changing managerial cognitions emerged that was associated with differences in the development of dynamic capabilities. These "cognitive shifts" constitute a change in how managers understand, frame, and predominantly view the nature of dynamic capabilities in place. In this respect, the meta-synthesis illustrates managers as having preexisting cognitive representations that direct the way in which a dynamic capability is created. In dynamic environments that offer new follow-on opportunities, cognitive shifts enable managers to reinterpret the internal progress of dynamic capability development, its appropriateness, and consequently to orchestrate the activities necessary for an adjustment.

\section{Step 7: Building Theory From Meta-Synthesis}

As a result, this meta-synthesis reveals that in dynamic environments that offer new follow-on opportunities a cognitive shift enables managers rendering an exercised dynamic capability more appropriate. By synthesizing evidence around a variety of different cognitive aspects in dynamic capability development from diverse settings, the concept of cognitive shifts is offered. The concept of cognitive shifts links back to a processual perspective on the development of dynamic capabilities in disruptive environmental changes. Scholars have acknowledged that managerial cognition can make a difference in directing the development of dynamic capabilities (Gavetti, 2005). Managers create cognitive representations to perceive environmental changes and to facilitate information processing (Helfat et al., 2007). This meta-synthesis shows that managerial cognitive representations are not to be understood as rigid mental models. However, the concept of cognitive shifts underscores that managers need to undergo a change in their thinking, thereby being capable of uncoupling from past experience and dissociating from current business assumptions and, thus, to generate a more complete picture of the relevance and appropriateness of extant capabilities. This does not mean that a shift in cognition necessarily leads to discontinuing the exercise of dysfunctional dynamic capabilities. However, if managers reinterpret or rethink the nature and appropriateness of dynamic capabilities in place, they may orchestrate the multilevel routines necessary to actualize a dynamic capability. Overall, the concept of cognitive shifts makes a contribution as it breaks down the hard-to-define area of cognitive processes into the discrete event of a shift in managerial cognitive representations that can be isolated and analyzed and is a broad enough construct to map the full territory of dynamic capabilities development. Therefore, subsequent studies can build on this meta-synthesis by using the concept of cognitive shifts as input for making decisions about samples, contexts, or variables to include in the theory-testing framework.

\section{Step 8: Discussion}

In a final step, general limitations about heterogeneity in the primary studies or the way the metasynthesis was conducted need to be discussed. This meta-synthesis entails a consistent set of qualitative case studies that all refer to a similar understanding of the concept of managerial cognition and of dynamic capabilities and use rigorous and sound methodologies. A limitation results from restricting the meta-synthesis study to 7 qualitative case studies as compared to a set of 30 studies initially identified in the field. Being very inclusive with regard to the studies incorporated entails the risks of reducing the range of interpretations of a phenomenon. Nevertheless, I maintain these results constitute a valuable contribution to managerial cognition in the development of dynamic capabilities. In this respect, this meta-synthesis goes beyond recent reviews conducted in the field of dynamic capability research. While these reviews mostly rely on a representative sample of published studies to generate a conceptual consolidation, this meta-synthesis offers an empirical consolidation based on an exhaustive search strategy. As such, all of the dynamic capabilities' research published from 1997 
to 2012 was located, thereby including business areas such as innovation (e.g., Journal of Product Innovation) or entrepreneurship (e.g., Entrepreneurship Theory and Practice, Strategic Entrepreneurship Journal).

\section{Discussion}

In this article, I offer a distinction among research syntheses as aggregation, interpretation, and translation that emerges from the basic paradigmatic positions inherent in organizational research. By following interpretation synthesis from a postpositivistic point of view, this article makes a contribution by providing the research design of a meta-synthesis. The goal of a meta-synthesis is to analyze constructs, key variables, and underlying relationships across a set of primary qualitative case studies to arrive at a refined, an extended or even new theory. In the following, I discuss the potential prospects as well as the challenges of the meta-synthesis and provide evidence that establishes its merits for accumulating knowledge.

First, a meta-synthesis of qualitative case studies is proposed to have major potential in synthesizing qualitative evidence on a particular topic to build theory. As opposed to reviewing an existing intellectual territory to formulate new research questions or future research directions (Tranfield et al., 2003), the aim of a meta-synthesis is to build theory, thereby moving from substantive theories that are grounded in particular research contexts to a more generic theory with a broader application. In this article, I argue that a meta-synthesis has the potential to support research to progress by offering a window for conducting a more deductive theory testing design on the foundations that the meta-synthesis provided. For example, in the field of dynamic capabilities, there are a series of qualitative studies offering a fragmented, isolated picture of a variety of different aspects around managerial cognitive processing. The design of a meta-synthesis allows researchers to accumulate rich, primary evidence and to generate theory that subsequent studies can build on. Accordingly, a meta-synthesis aids in developing inductive theories that can form bridges from rich qualitative evidence to more deductive research, thereby moving to higher levels of abstraction (Eisenhardt \& Graebner, 2007; Shah \& Corley, 2006).

Second, building theory out of published case studies holds great potential especially if a reliable synthesis process is augmented through the application of the rigorous procedures described here. Throughout the meta-synthesis process, the researchers face the challenge of evaluating various available options to make informed methodological choices that are best suited for the synthesis purpose. However, I advocate that it is not standardization or uniformity that is desirable; rather it is the transparent, systematic, and explicit reporting of these choices that ensures reliability in this type of research synthesis. This codification allows the readers to retrace the certain paths of the meta-synthesis process as well as to critically evaluate the process and its associated product. For example, by providing a meta-synthesis protocol, transparently reporting the literature search and the inclusion/exclusion criteria as well as indicating the procedures for coding and analysis, not only the validity of the results, but also the reliability of the meta-synthesis study itself can be ensured; an aspect that is generally considered as one of the key advantages of research synthesis over literature reviews (Aguinis, Pierce, et al., 2011; Aytug et al., 2012; Dalton \& Dalton, 2008).

Third, the greatest challenge that a qualitative synthesis faces is viewed in the heterogeneity inherent in the primary studies' underlying paradigmatic perspectives, methods, and quality (Noblit $\&$ Hare, 1988; Rousseau et al., 2008). The meta-synthesis design provided here adopts a more narrow approach in that it is restricted to studies following a case study approach as opposed to including qualitative studies of any type. Although the inclusion of a broad range of studies may contribute to the interpretation of a phenomenon (Sandelowski \& Barroso, 2007), I propose that embracing papers with the same method is beneficial as methodological underpinnings are respected and meaning can be preserved while new meanings could also emerge. However, heterogeneity always pertains to variety in the studies' context. Consequently, a major challenge in meta-synthesis stems from empirical evidence being framed within the contextual settings in which the primary data were 
conducted, analyzed, and interpreted. Acknowledging the contextual conditions is of central importance as these conditions provide the potential to account for larger moderating effects (Cortina, 2003). To address contextual considerations, the meta-synthesist needs to engage in the preservation of meaning from the original texts as far as possible. This requirement of contextual sensitivity is one that the meta-synthesist has to carefully reflect on in each decision point that he/she faces during the synthesis process. To ensure sensitivity toward the contextual considerations of any empirical material, ideally, a meta-synthesis should only be conducted by a team of trained researchers. Especially the contribution of experts in qualitative research who are also trained in conducting a metasynthesis would be beneficial for ensuring a rigorous synthesis process.

Finally, the view taken here is that the meta-synthesis is most beneficial in intermediate or mature fields of research that are characterized by unique phenomena and a lack of adequate quantitative measures (Edmondson \& McManus, 2007). More specifically, a conventional literature review or a systematic review can be seen as especially appropriate to conceptually assess and map the state of the art of a nascent field. Within a field that is progressing, more empirical research is evolving and a meta-synthesis can be helpful in converging this growing body of knowledge into new insight. For example, more intermediate fields such as the dynamic capabilities approach are particularly promising for a meta-synthesis where a continuously increasing body of empirical studies explores new constructs and/or provisional theoretical relationships. Indeed, a meta-synthesis cannot be performed without data. However, I suggest that it is not only the number of studies conducted that justifies a meta-synthesis; rather, I follow Cooper's (2010) notion that it is the fresh insights a synthesis can bring to a field that legitimates its course of action.

\section{Conclusion}

In organizational and management research, there is a need to assemble a field's full weight of scientific knowledge into a full understanding of a phenomenon (Hunter et al., 1982; Rousseau et al., 2008). In this article, I develop the meta-synthesis design as a rigorous and systematic way of synthesizing qualitative case studies to build theory. Rather than meta-analyzing quantitative findings in an additive logic, the meta-synthesis seeks to move a body of knowledge forward by interpreting primary qualitative evidence across different contexts to come to a higher replicability of theory.

Nevertheless, this meta-synthesis design has raised a number of issues that require further discussion and consideration. First, the research design of a meta-synthesis proposed in this article has arrived at stages of analysis that seek to satisfy the criteria of validity and reliability. Thus, I advocate that stating and applying criteria for rigorous work is to be viewed as a critical part of conducting a meta-synthesis. In particular, it is key to the validity and reliability of a synthesis to acknowledge the potential bias that may stem from an incomplete literature research or from data being incorrectly extracted from primary studies (Aytug et al., 2012; Cooper, 2010). Future researchers should engage in minimizing bias and improving rigor at every stage of the synthesis, thereby ensuring that the conduct of a meta-synthesis meets the same standards as the primary studies under synthesis. Second, in this article, a set of techniques and procedures is provided that are beneficial for analyzing primary qualitative evidence at a within-case level or an across-case level. More generally, I propose that the procedures of coding and analysis developed for primary qualitative research seem to be applicable to the meta-synthesis as they allow for iterative comparisons across qualitative data sources (Miles \& Huberman, 1994). However, future research should identify and explore further qualitative as well as quantitative methods that may bear potential in these analysis issues and provide additional ways of synthesizing qualitative evidence. Taken together, in this article I advocate that advancing management theory does not only evolve from scholars engaging in field research — studying real people, real problems, and real organizations (Edmondson \& McManus, 2007) — but also by researchers entangling in the accumulation of knowledge already existing in a field. 


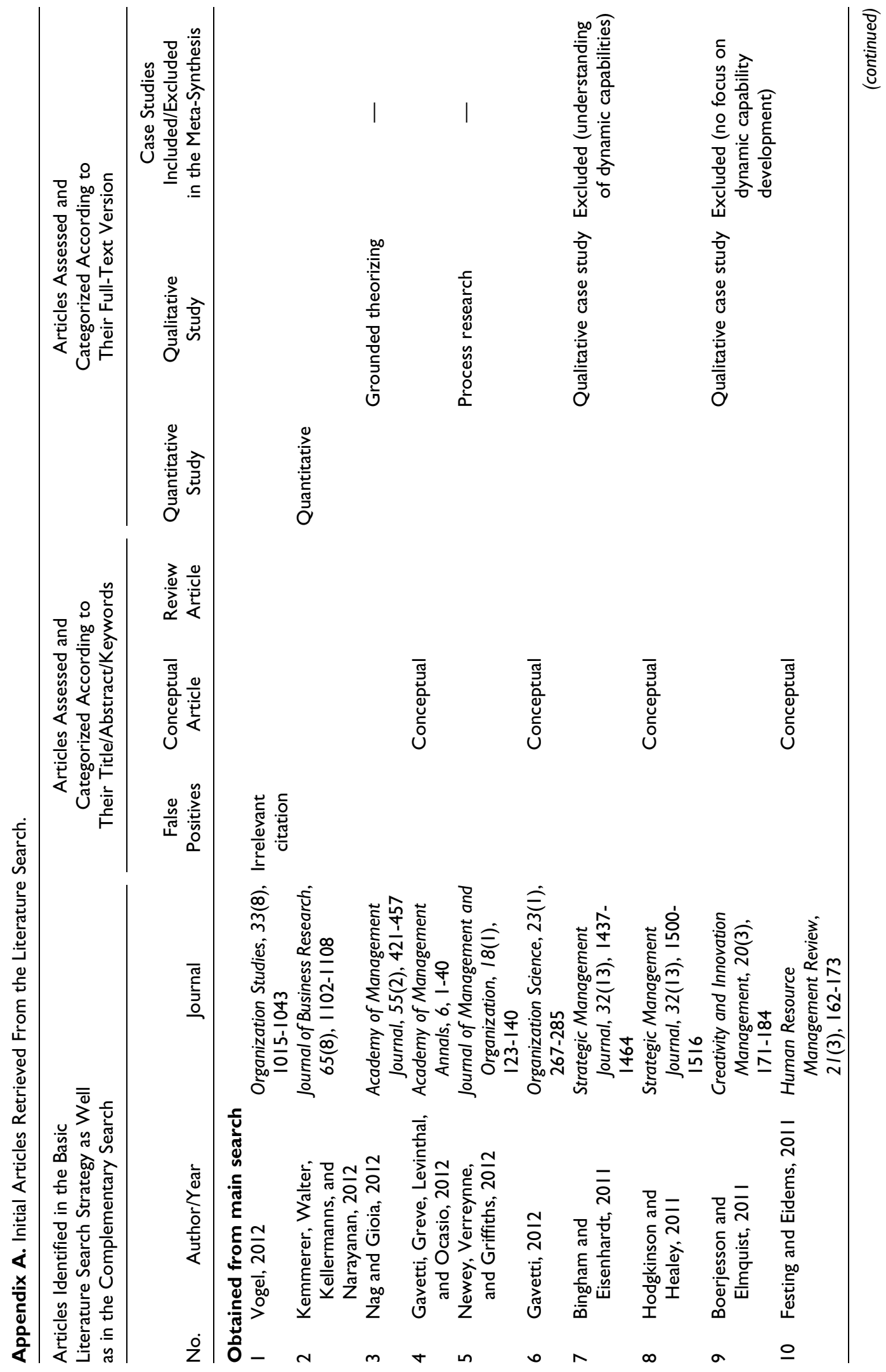




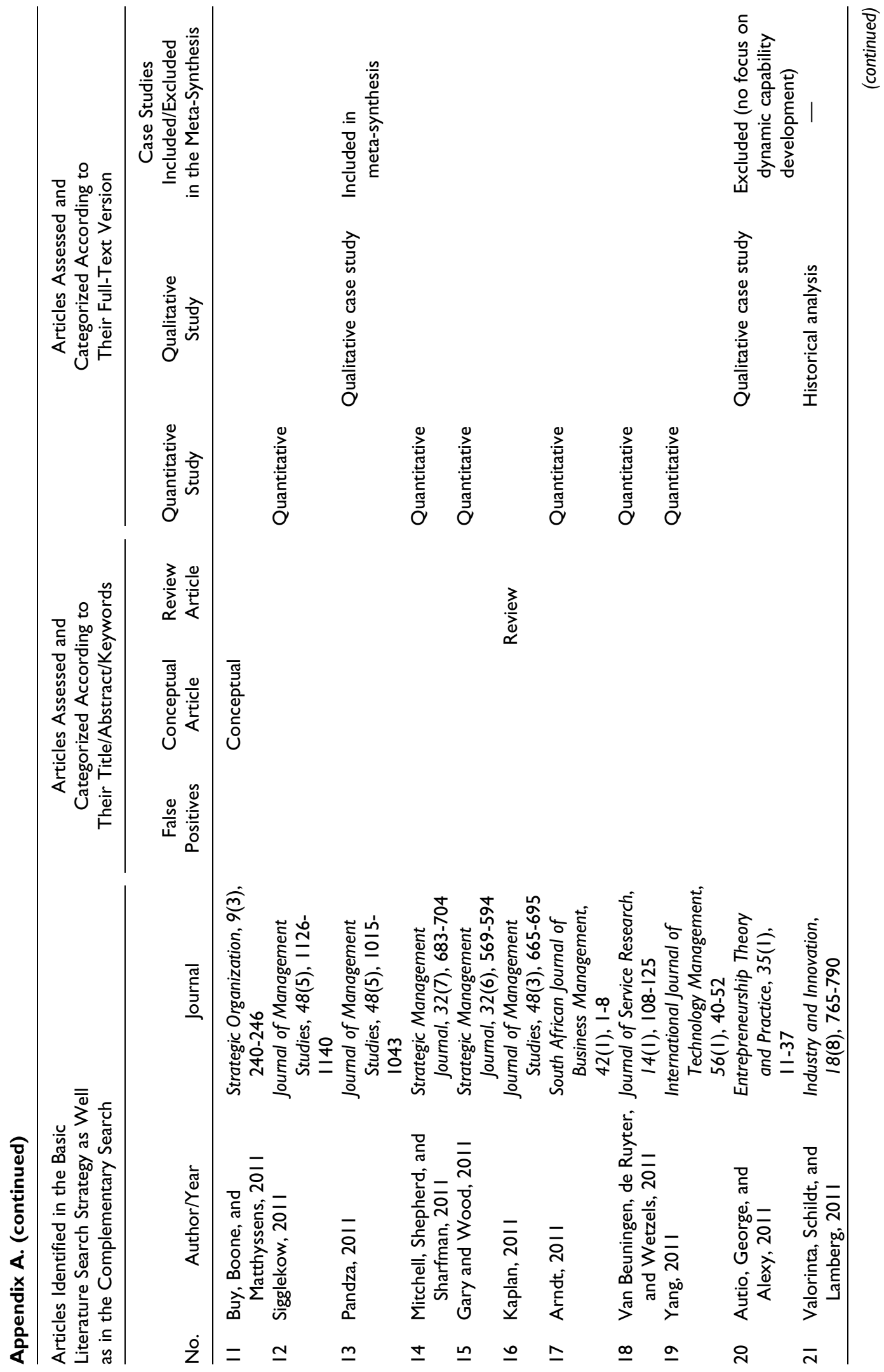




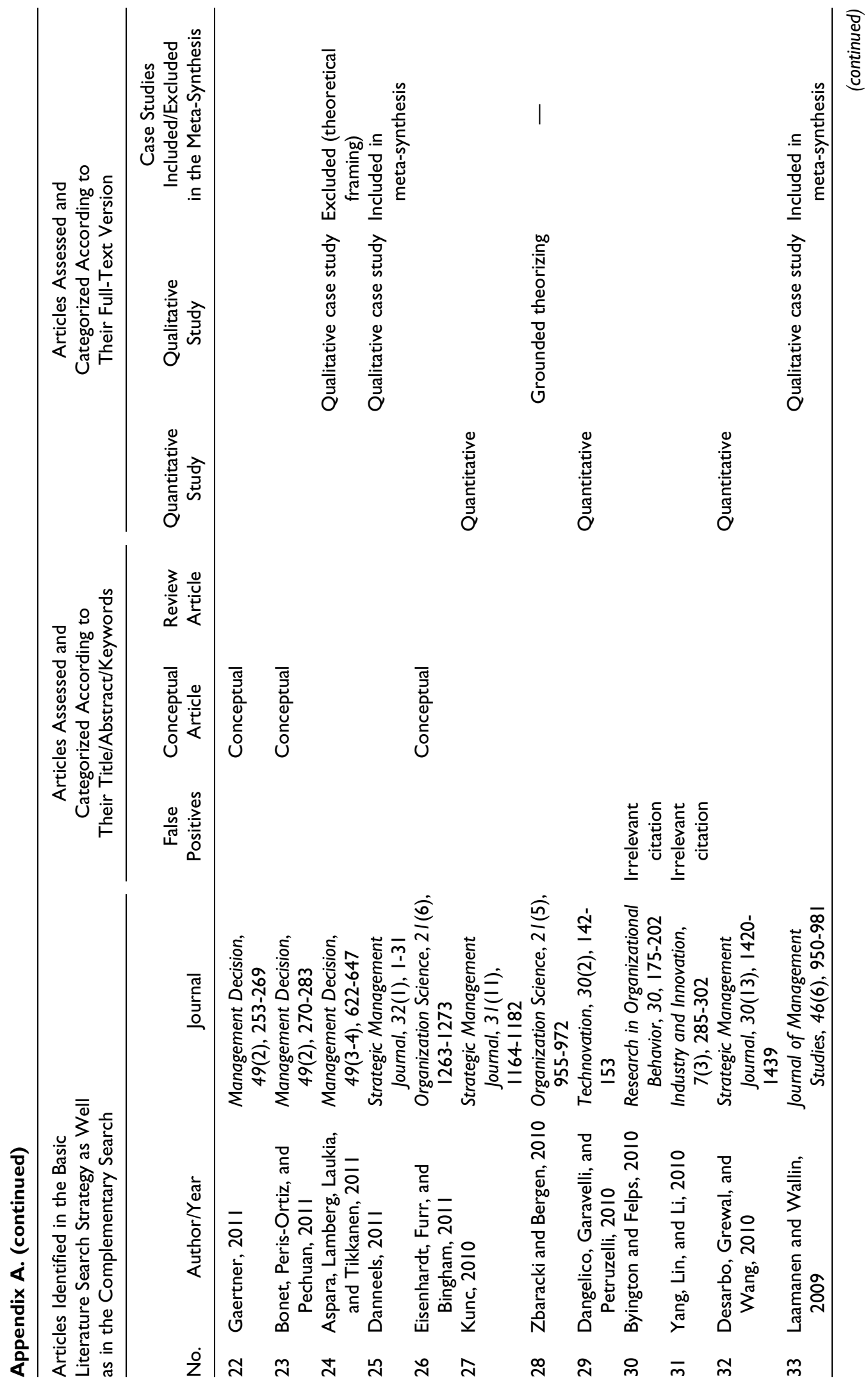




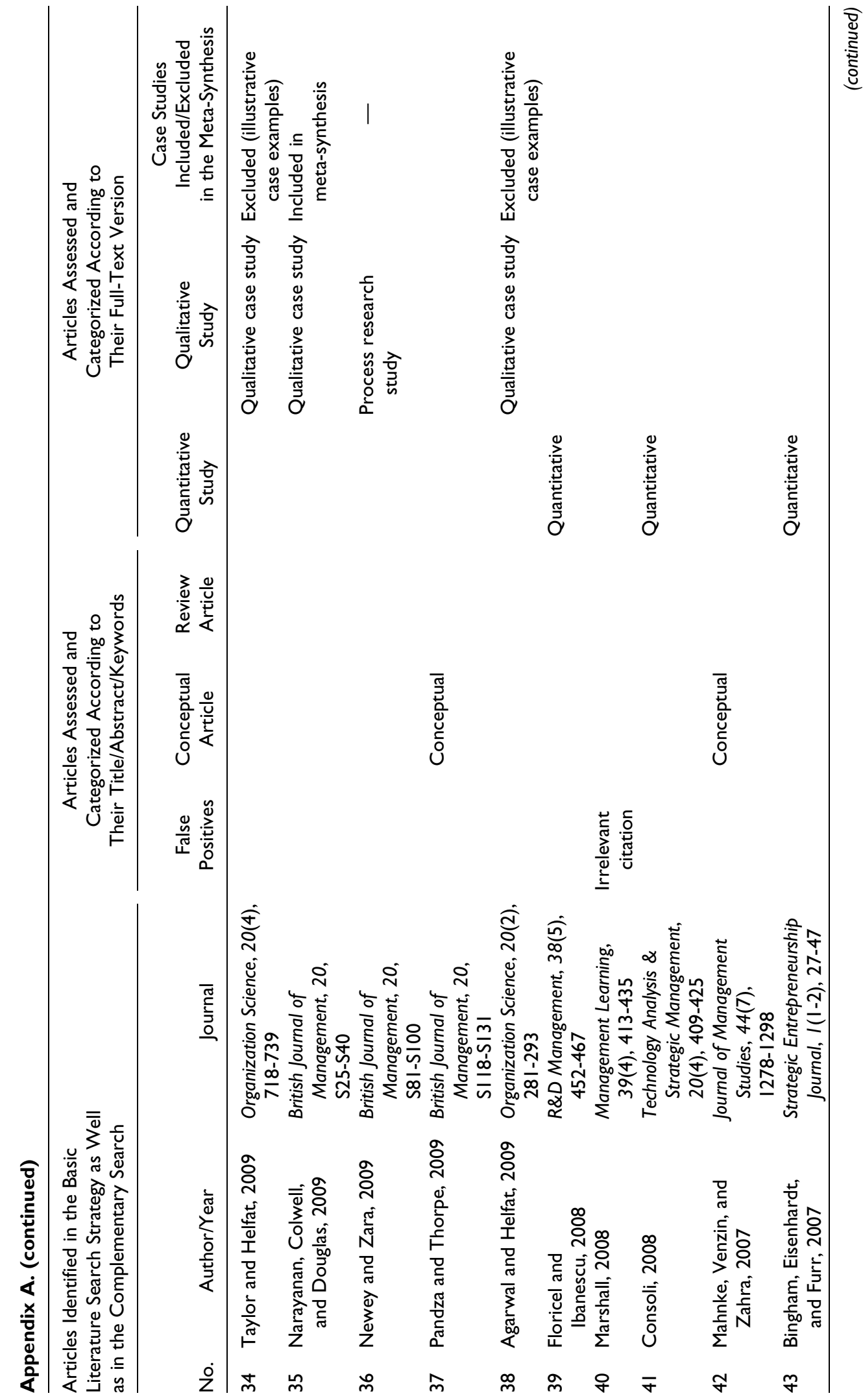




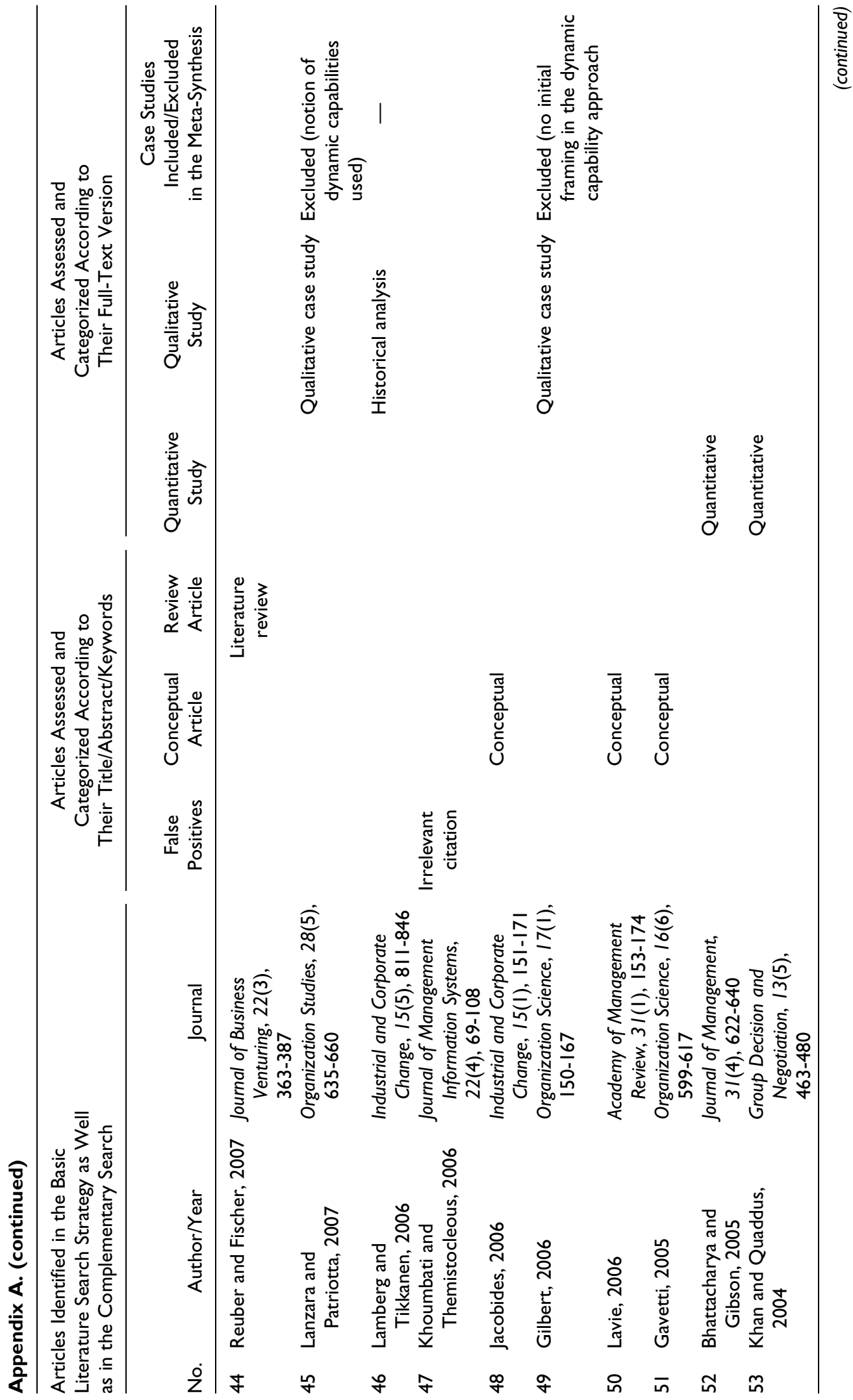




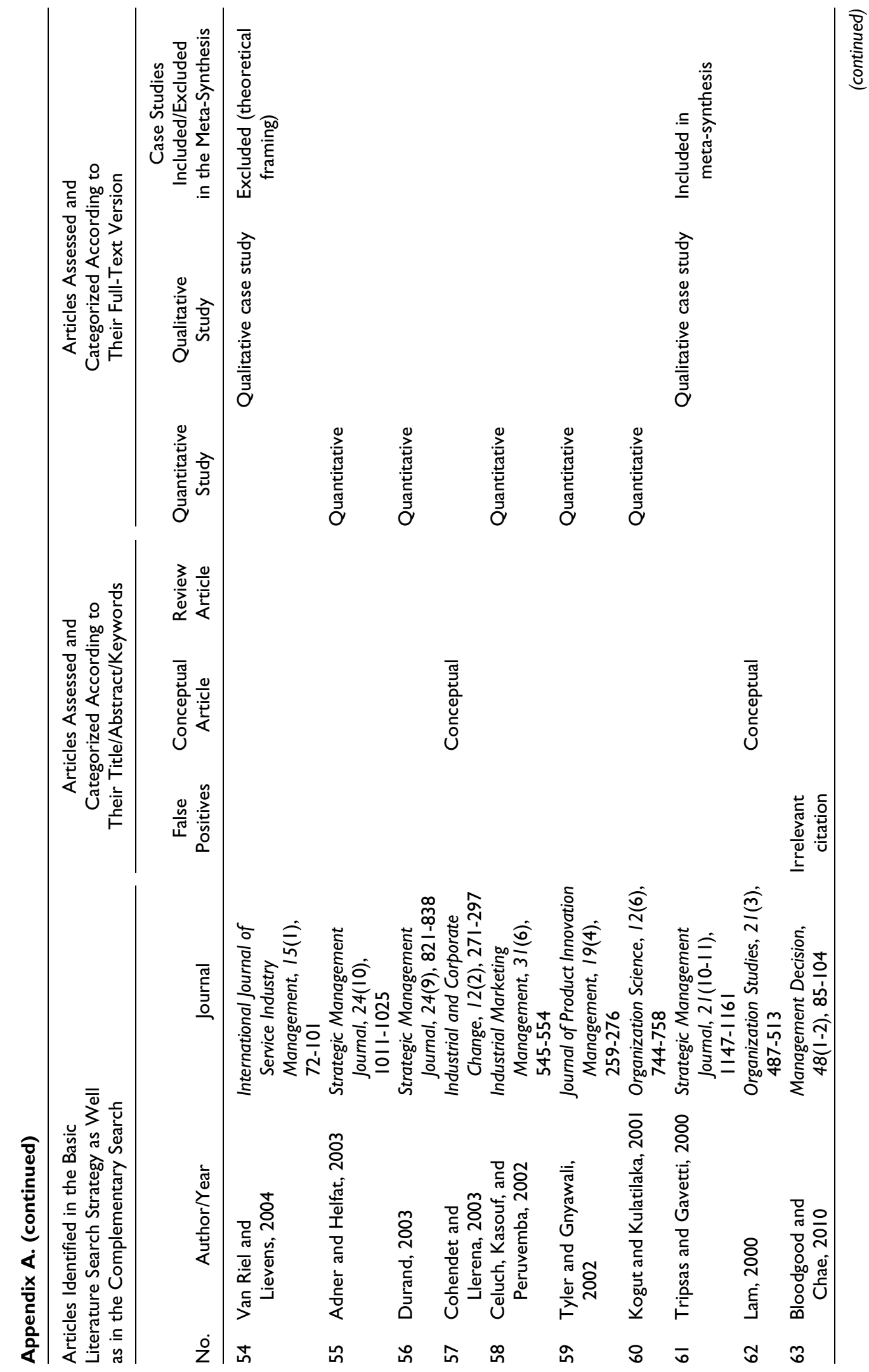




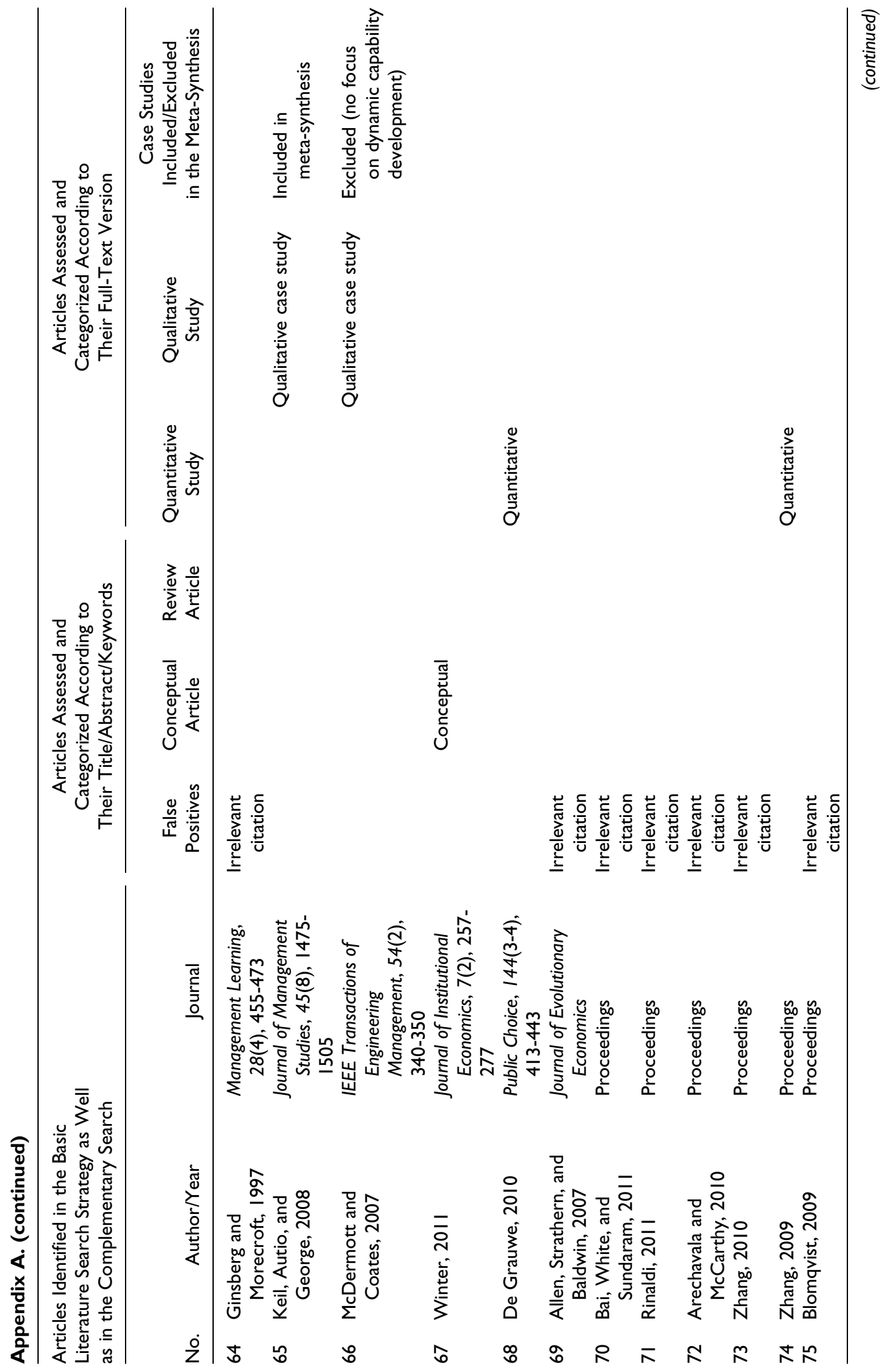




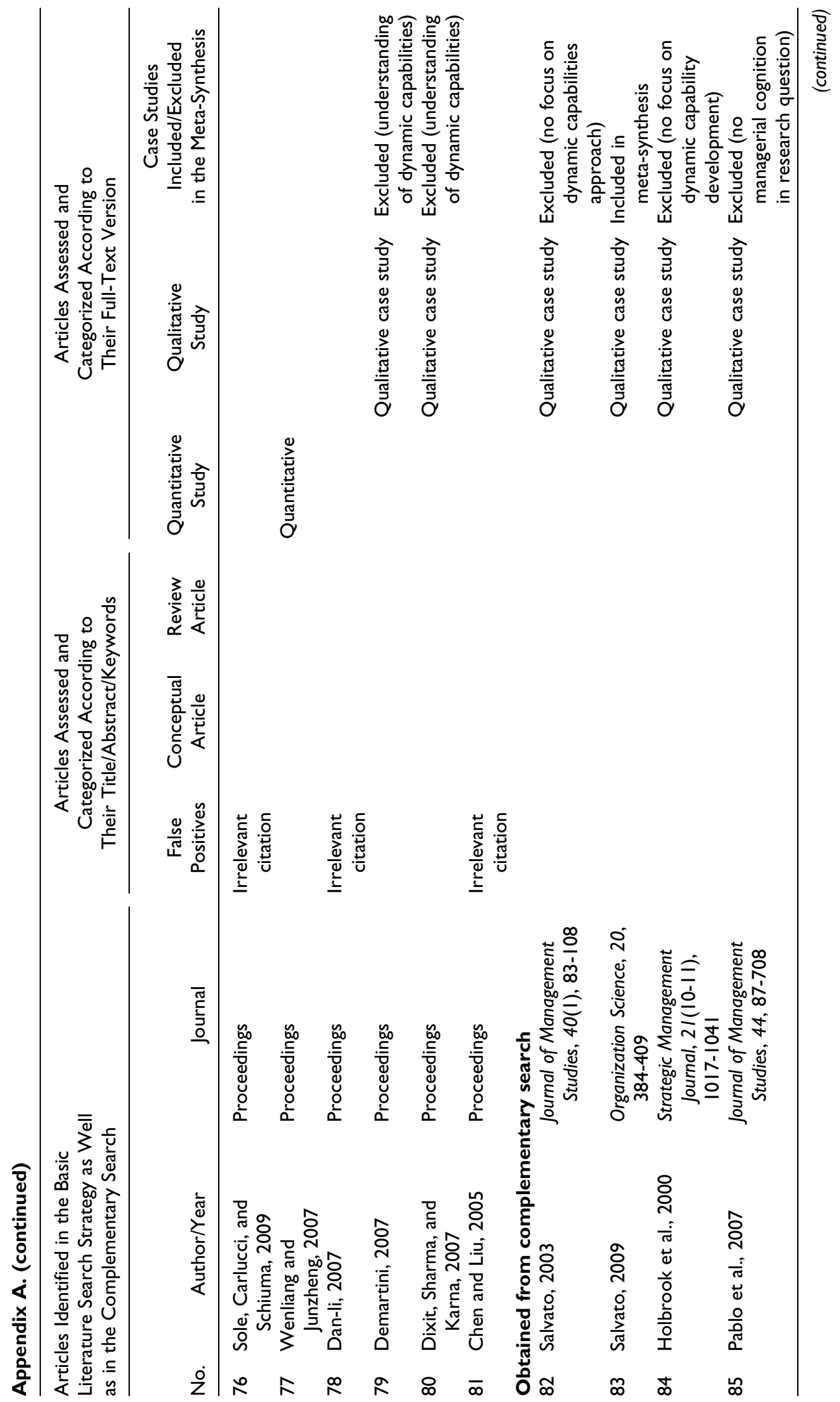




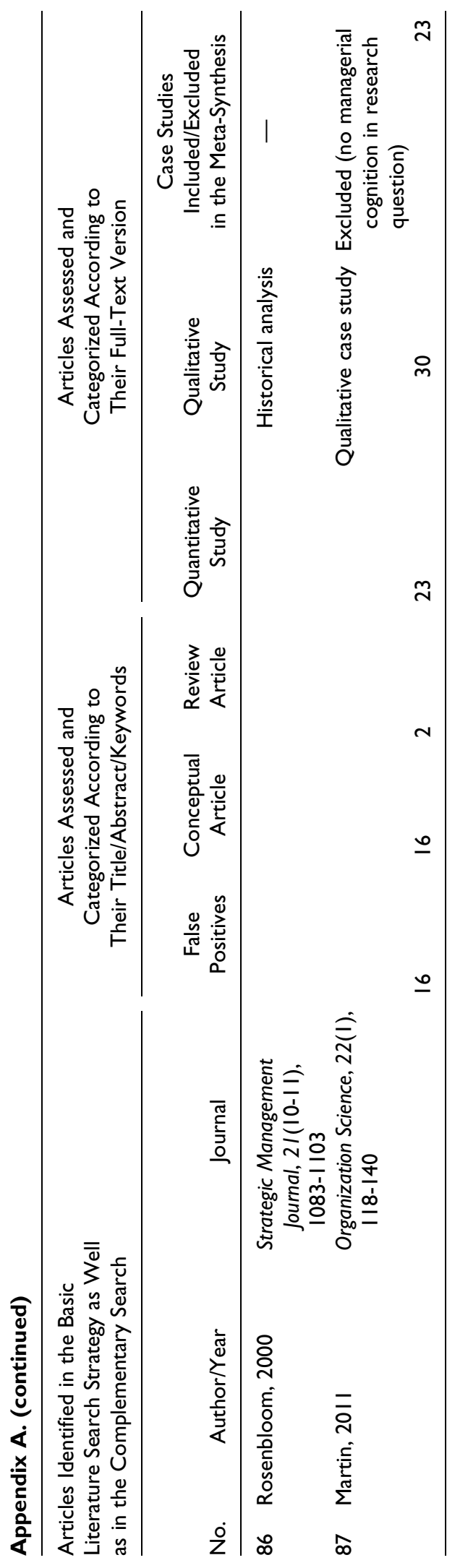




\section{Appendix B}

\section{List of Studies Included in the Meta-Synthesis}

Danneels, E. (2010). Trying to become a different type of company: Dynamic capability at Smith Corona. Strategic Management Journal, 32, 1-31.

Keil, T., Autio, E., \& George, G. (2008). Corporate venture capital, disembodied experimentation, and capability development. Journal of Management Studies, 45, 1475-1505.

Laamanen, T., \& Wallin, J. (2009). Cognitive dynamics of capability development paths. Journal of Management Studies, 46, 950-981.

Narayanan, V. K., Colwell, K., \& Douglas, F. L. (2009). Building organizational and scientific platforms in the pharmaceutical industry. A process perspective on the development of dynamic capabilities. British Journal of Management, 20, 25-40.

Pandza, K. (2011). Why and how will a group act autonomously to make an impact on the development of organizational capabilities? Journal of Management Studies, 48, 1015-1043.

Salvato, C. (2009). Role of ordinary activities in evolution of product development processes. Organization Science, 20, 384-409.

Tripsas, M., \& Gavetti, G. (2000). Capabilities, cognition, and inertia: Evidence from digital imaging. Strategic Management Journal, 21, 1147-1161.

\section{Declaration of Conflicting Interests}

The author(s) declared no potential conflicts of interest with respect to the research, authorship, and/or publication of this article.

\section{Funding}

The author(s) received no financial support for the research, authorship, and/or publication of this article.

\section{References}

Aguinis, H., Dalton, D. R., Bosco, F. A., Pierce, C. A., \& Dalton, C. M. (2011). Meta-analytic choices and judgment calls: Implications for theory building and testing, obtained effect sizes, and scholarly impact. Journal of Management, 37, 5-38.

Aguinis, H., Pierce, C. A., Bosco, F. A., Dalton, D. R., \& Dalton, C. M. (2011). Debunking myths and urban legends about meta-analysis. Organizational Research Methods, 14, 306-331.

Aguinis, H., Sturman, M. C., \& Pierce, C. A. (2008). Comparison of three meta-analytic procedures for estimating moderating effects of categorical variables. Organizational Research Methods, 11, 9-34.

Augier, M., \& Teece, D. J. (2009). Dynamic capabilities and the role of managers in business strategy and economic performance. Organization Science, 20, 410-421.

Aytug, Z. G., Rothstein, H. R., Zhou, W., \& Kern, M. C. (2012). Revealed or concealed? Transparency of procedures, decisions, and judgment calls in meta-analyses. Organizational Research Methods, 15, 103-133.

Burawoy, M. (1998). The extended case method. Sociological Theory, 16, 4-33.

Campbell, D. T. (1974). Evolutionary epistemology. In P. A. Schilpp (Ed.), The philosophy of Karl Popper (Vol. 14, pp. 413-463). LaSalle, IL: Open Court.

Carlson, K. D., \& Ji, F. X. (2011). Citing and building on meta-analytic findings: A review and recommendations. Organizational Research Methods, 14, 696-717.

Colquitt, J. A., \& Zapata-Phelan, C. P. (2007). Trends in theory building and theory testing: A five-decade study of Academy of Management Journal. Academy of Management Journal, 50, 1281-1303.

Cooper, H. (2010). Research synthesis and meta-analysis: A step-by-step approach (4th ed.). Thousand Oaks, CA: Sage. Cortina, J. M. (2003). Apples and oranges (and pears, oh my!): The search for moderators in meta-analysis. Organizational Research Methods, 6, 415-439. 
Dalton, D. R., Aguinis, H., Dalton, C. M., Bosco, F. A., \& Pierce, C. A. (2012). Revisiting the file drawer problem in meta-analysis: An assessment of published and unpublished correlation matrices. Personnel Psychology, 65, 221-249.

Dalton, D. R., \& Dalton, C. M. (2008). Meta-analyses: Some very good steps toward a bit longer journey. Organizational Research Methods, 11, 127-147.

Denyer, D., \& Tranfield, D. (2003). Towards a methodology for developing evidence-informed management knowledge by means of systematic review. British Journal of Management, 14, 207-222.

Di Stefano, G., Peteraf, M., \& Verona, G. (2010). Dynamic capabilities deconstructed. A bibliographic investigation into the origins, development and future directions of the research domain. Industrial and Corporate Change, 19, 1187-1204.

Duriau, V. J., Reger, R. K., \& Pfarrer, M. D. (2007). A content analysis of the content analysis literature in organization studies: Research themes, data sources, and methodological refinements. Organizational Research Methods, 10, 5-33.

Edmondson, A. C., \& McManus, S. E. (2007). Methodological fit in management field research. Academy of Management Review, 32, 1155-1179.

Eisenhardt, K. M. (1989). Building theories from case study research. Academy of Management Review, 14, 532-550.

Eisenhardt, K. M., \& Graebner, M. E. (2007). Theory building from cases: Opportunities and challenges. Academy of Management Journal, 50, 25-32.

Eisenhardt, K. M., \& Martin, J. (2000). Dynamic capabilities: What are they? Strategic Management Journal, 21, 1105-1121.

Flyvbjerg, B. (2011). Case study. In N. K. Denzin \& Y. S. Lincoln (Eds.), Handbook of qualitative research (4th ed., pp. 301-316). Thousand Oaks, CA: Sage.

Gavetti, G. (2005). Cognition and hierarchy: Rethinking the microfoundations of capabilities development. Organization Science, 16, 599-617.

Gephart, R. P. (2004). From the editors: Qualitative research and the Academy of Management Journal. Academy of Management Journal, 47, 454-462.

Gioia, D. A., \& Pitre, E. (1990). Multi-paradigm perspectives in theory building. Academy of Management Review, 15, 584-602.

Glass, G. V. (1977). Integrating findings: The meta-analysis of research. Review of Research in Education, 5, 351-379.

Guba, E. G., \& Lincoln, Y. S. (1994). Competing paradigms in qualitative research. In N. K. Denzin \& Y. S. Lincoln (Eds.), Handbook of qualitative research (pp. 105-117). Thousand Oaks, CA: Sage.

Guba, E. G., \& Lincoln, Y. S. (2005). Paradigmatic controversies, contradictions, and emerging influences. In N. K. Denzin \& Y. S. Lincoln (Eds.), The Sage handbook of qualitative research (3rd ed., pp. 191-215). Thousand Oaks, CA: Sage.

Hammersley, M., \& Gomm, R. (2002). Introduction. In M. Hammersley, R. Gomm, \& P. Foster (Eds.), Case study method: Key issues, key texts (pp. 1-16). Thousand Oaks, CA: Sage.

Helfat, C. E., Finkelstein, S., Mitchell, W., Peteraf, M., Singh, H., Teece, D. J., \& Winter, S. (2007). Dynamic capabilities: Understanding strategic change in organizations. Malden, MA: Blackwell.

Hunt, M. (1997). How science takes stock: The story of meta-analysis. New York: Russell Sage.

Hunter, J. E., Schmidt, F., \& Jackson, G. (1982). Meta-analysis: Cumulating research findings across studies. Beverly Hills, CA: Sage.

Jarzabkowski, P., \& Spee, A. P. (2009). Strategy as practice: A review and future directions for the field. International Journal of Management Reviews, 11, 1-14.

Kepes, S., Banks, G. C., McDaniel, M., \& Whetzel, D. L. (2012). Publication bias in organizational science. Organizational Research Methods, 15, 624-662.

Kisamore, J., \& Brannick, M. T. (2008). An illustration of the consequences of meta-analysis model choice. Organizational Research Methods, 11, 35-53.

Kuhn, T. S. (1962). The structure of scientific revolutions. Chicago, IL: University of Chicago.

Lincoln, Y. S., \& Guba, E. G. (1985). Naturalistic inquiry. Beverly Hills, CA: Sage. 
McDaniel, M. A., Rothstein, H. R., \& Whetzel, D. L. (2006). Publication bias: A case study of four test vendors. Personnel Psychology, 59, 927-953.

Miles, M. B., \& Huberman, A. M. (1994). Qualitative data analysis: An expanded sourcebook (2nd ed.). Thousand Oaks, CA: Sage.

Noblit, G. W., \& Hare, R. D. (1988). Meta-ethnography: Synthesizing qualitative studies. Qualitative research method series 11. London, UK: Sage.

Piekkari, R., Welch, C., \& Paavilainen, E. (2009). The case study as disciplinary convention: Evidence from international business journals. Organizational Research Methods, 12, 567-589.

Pratt, M. G. (2008). Fitting oval pegs into round holes: Tensions in evaluating and publishing qualitative research in top-tier North American journals. Organizational Research Methods, 11, 481-509.

Ridder, H.-G., Hoon, C., \& Baluch, A. M. (2012). Entering a dialogue: Positioning case study findings towards theory. British Journal of Management. Advance online publication. doi:10.1111/1467-8551.12000

Ridder, H.-G., Hoon, C., \& McCandless, A. (2009). The theoretical contribution of case study research to the field of strategy and management. In D. J. Ketchen \& D. D. Bergh (Eds.), Research methodology in strategy and management (Vol. 5, pp. 137-178). Oxford, UK: Elsevier.

Rousseau, D. M., Manning, J., \& Denyer, D. (2008). Evidence in management and organizational science: Assembling the field's full weight to scientific knowledge through synthesis. Academy of Management Annals, 2, 475-515.

Sandelowski, M., \& Barroso, J. (2007). Handbook for synthesizing qualitative research. New York, NY: Springer.

Schmidt, F. L. (2008). Meta-analysis: A constantly evolving research integration tool. Organizational Research Methods, 11, 96-113.

Shah, S. K., \& Corley, K. G. (2006). Building better theory by bridging the quantitative-qualitative divide. Journal of Management Studies, 43, 1821-1835.

Sigglekow, N. (2007). Persuasion with case studies. Academy of Management Journal, 50, 20-24.

Snow, D. (2004). Thoughts on alternative pathways to theoretical development: Theory generation, extension and refinement. In C. C. Ragin, J. Nagel, \& P. White (Eds.), Workshop on scientific foundations of qualitative research (pp. 133-136). Arlington, VA: National Science Foundation.

Stake, R. E. (2005). Qualitative case studies. In N. K. Denzin \& Y. S. Lincoln (Eds.), The Sage handbook of qualitative research (3rd ed., pp. 443-465). Thousand Oaks, CA: Sage.

Teece, D. J., Pisano, G., \& Shuen, A. (1997). Dynamic capabilities and strategic management. Strategic Management Journal, 18, 509-533.

Tranfield, D., Denyer, D., \& Smart, P. (2003). Towards a methodology for developing evidence-informed management knowledge by means of systematic review. British Journal of Management, 14, 207-222.

Wang, C., \& Ahmed, P. (2007). Dynamic capabilities: A review and research agenda. International Journal of Management Reviews, 9, 31-51.

Wanous, J. P., Sullivan, S. E., \& Malinak, J. (1989). The role of judgment calls in meta-analysis. Journal of Applied Psychology, 74, 259-264.

Weick, K. E. (1989). Theory construction as disciplined imagination. Academy of Management Review, 14, 516-531. Yin, R. (2009). Case study research: Design and methods (3rd ed.). Thousand Oaks, CA: Sage.

\section{Author Biography}

Christina Hoon is a postdoctoral researcher in the Institute of Human Resource Management at the Leibniz University of Hannover, Germany. She received her $\mathrm{PhD}$ from the Leibniz University of Hannover. Her research focuses on dynamic capabilities, strategic change, and research methods. Her main research interests are in the area of organizational and strategic change in pluralistic settings with an emphasis on strategy as practice, organizational sensemaking, dynamic capabilities, and qualitative research, in particular case study methods and qualitative meta-synthesis. Her work is published in journals including Human Relations, Research Methodology in Strategy and Management, and British Journal of Management. 